\title{
Exploring the Fasciola hepatica tegument proteome
}

\author{
R. Alan Wilson ${ }^{\mathrm{a}, *}$, Janelle M. Wright ${ }^{\mathrm{b}}$, William de Castro-Borges ${ }^{\mathrm{a}, \mathrm{c}}$, Sophie J. Parker-Manuel ${ }^{\mathrm{a}}$, \\ Adam A. Dowle ${ }^{\mathrm{d}}$, Peter D. Ashton ${ }^{\mathrm{a}}$, Neil D. Young ${ }^{\mathrm{e}}$, Robin B. Gasser ${ }^{\mathrm{e}}$, Terry W. Spithill ${ }^{\mathrm{b}, \mathrm{f}}$ \\ ${ }^{a}$ Centre for Immunology and Infection, Department of Biology, University of York, Heslington, York YO10 5DD, United Kingdom \\ ${ }^{\mathrm{b}}$ School of Animal and Veterinary Sciences, Charles Sturt University, Wagga Wagga, NSW 2650, Australia \\ ${ }^{\mathrm{C}}$ Departamento de Ciências Biológicas, Universidade Federal de Ouro Preto, CEP - 35400-000 Ouro Preto, MG, Brazil \\ ${ }^{\mathrm{d}}$ Centre of Excellence in Mass Spectrometry, Technology Facility, Department of Biology, University of York, Heslington, York YO10 5DD, United Kingdom \\ e Department of Veterinary Science, The University of Melbourne, Parkville, Victoria 3052, Australia \\ ${ }^{\mathrm{f}}$ Department of Agricultural Sciences and Centre for AgriBioscience, La Trobe University, Bundoora, Victoria 3083, Australia
}

\section{A R T I C L E I N F O}

\section{Article history:}

Received 15 June 2011

Received in revised form 29 August 2011

Accepted 30 August 2011

Available online 5 October 2011

\section{Keywords:}

Fasciola hepatica

Liver fluke

Tegument proteome

Excretory-secretory proteins

Tandem mass spectrometry

Morphology

Vomitus

\begin{abstract}
A B S T R A C T
The surface tegument of the liver fluke Fasciola hepatica is a syncytial cytoplasmic layer bounded externally by a plasma membrane and covered by a glycocalyx, which constitutes the interface between the parasite and its ruminant host. The tegument's interaction with the immune system during the fluke's protracted migration from the gut lumen through the peritoneal cavity and liver parenchyma to the lumen of the bile duct, plays a key role in the fluke's establishment or elimination. However, little is known about proteins of the tegument surface or its secretions. We applied techniques developed for the blood fluke, Schistosoma mansoni, to enrich a tegument surface membrane preparation and analyse its composition by tandem mass spectrometry using new transcript databases for $F$. hepatica. We increased the membrane and secretory pathway components of the final preparation to $\sim 30 \%$, whilst eliminating contaminating proteases. We identified a series of proteins or transcripts shared with the schistosome tegument including annexins, a tetraspanin, carbonic anhydrase and an orthologue of a host protein (CD59) that inhibits complement fixation. Unique to $F$. hepatica, we also found proteins with lectin, cubulin and von Willebrand factor domains plus 10 proteins with leader sequences or transmembrane helices. Many of these surface proteins are potential vaccine candidates. We were hampered in collecting tegument secretions by the propensity of liver flukes, unlike blood flukes, to vomit their gut contents. We analysed both the 'vomitus' and a second supernatant released from haematin-depleted flukes. We identified many proteases, some novel, as well as a second protein with a von Willebrand factor domain. This study demonstrates that components of the tegumental surface of $F$. hepatica can be defined using proteomic approaches, but also indicates the need to prevent vomiting if tegument secretions are to be characterised.
\end{abstract}

Crown Copyright $\odot 2011$ Published by Elsevier Ltd. on behalf of Australian Society for Parasitology Inc. All rights reserved.

\section{Introduction}

Fasciolosis is a major zoonotic disease caused by the liver flukes Fasciola hepatica and Fasciola gigantica, which are flatworm parasites transmitted following ingestion of herbage contaminated with the infective stage (metacercariae). The infection is a significant constraint on ruminant productivity in Europe, Africa, Asia, the Americas and Australasia, with prevalences in some regions of $80-100 \%,>600$ million animals at risk, and annual economic losses of $>$ US $\$ 3$ billion (Piedrafita et al., 2004, 2007). It is recognised by the World Health Organization (WHO) as a major food-borne problem, with up to 17 million people infected and

\footnotetext{
* Corresponding author. Tel.: +44 1904 328600; fax: +44 1904328505 .

E-mail address: raw3@york.ac.uk (R.A. Wilson).
}

180 million at risk. High but localised prevalence (72-100\%) has been recorded in Bolivia ( $>1$ million cases), Peru, Africa and the Middle East (Mas-Coma et al., 2005; McManus and Dalton, 2006) with up to 830,000 people infected in Egypt alone (Mas-Coma et al., 2005). Triclabendazole is the drug of choice for treatment of fasciolosis but resistance, first observed in Australia in 1995, is now widespread in Europe (Fairweather, 2009). In endemic areas such as Bolivia and Egypt, resistance threatens to make the disease untreatable and new methods of control are urgently needed.

The production of an effective vaccine may be a sustainable control strategy. However, although there has been a considerable effort to develop such a vaccine, current experimental approaches suffer from two limitations: efficacy is variable between animals and the level achieved to date (38-72\%) falls short of the $>80 \%$ protection generally agreed as necessary for a commercially viable 
product for cattle (Hillyer, 2005; McManus and Dalton, 2006). Two candidate vaccines (leucine amino peptidase and SAP2) have shown an efficacy of $>80 \%$ in single animal trials but require validation in cattle (Piacenza et al., 1999; Espino and Hillyer, 2004; Acosta et al., 2008). The development of anti-Fasciola vaccines has been hindered by lack of insights into natural acquired immune mechanisms expressed by ruminant hosts against fluke infection and knowledge of immune correlates of protection. A better understanding of the targets of acquired immunity in cattle is required if we are to devise a commercial vaccine for large ruminants.

There is good evidence from several studies that livestock can acquire resistance to Fasciola. Vaccination using either irradiated metacercariae, drug abbreviated infection, parasite extracts or defined antigens can induce $48-89 \%$ reductions in fluke burdens in ruminants (Dalton et al., 1996; Morrison et al., 1996; Piacenza et al., 1999; Hoyle et al., 2003; Piedrafita et al., 2004; Hillyer, 2005; McManus and Dalton, 2006; Golden et al., 2010). These results demonstrate that Fasciola antigens can elicit high levels of immunity in cattle and sheep, suggesting that the goal of $>80 \%$ protection is achievable. The key step now is to identify the parasite stage and antigens driving the acquired protective response. In cattle or sheep where protection has been demonstrated following vaccination or due to natural resistance, clinical serology has revealed that killing of parasites occurs within approximately 6 weeks of infection but only after some damage to the liver parenchyma (Dalton et al., 1996; Roberts et al., 1997; Piacenza et al., 1999; Hoyle et al., 2003; Piedrafita et al., 2004). These observations suggest that the newly excysted juvenile (NEJ) or immature parasite migrating in the liver, not the adult fluke, is the target of the acquired immune response but the nature of this effector response acting in vivo is not clear. Moreover, a vaccine targeting the NEJ, which suppressed or eliminated invasion of the liver parenchyma, would minimise liver pathology and reduce production losses in livestock. Using in vitro studies, it has been shown that $F$. hepatica NEJs are susceptible to antibody-dependent cell cytotoxicity (ADCC) mediated by nitric oxide (NO) released by rat peritoneal macrophages (Piedrafita et al., 2001, 2004). An ADCC immune mechanism effective against $F$. gigantica NEJs in vitro has also been reported in sheep and in this case killing was mediated by superoxide radicals (not NO) produced by macrophages (Piedrafita et al., 2007). Although an ADCC mechanism effective against liver flukes has not been demonstrated in vivo, these results suggest the possibility that antigens on the surface tegument of NEJs/ immature flukes, recognised by immune sera, may represent targets of the proposed ADCC mechanism and that these antigens represent novel vaccine candidates. Although the immune mechanisms that kill Fasciola in cattle have not been resolved, we have proposed that they may involve an ADCC mechanism similar to that observed against $F$. gigantica in sheep (Piedrafita et al., 2004).

The tegument of flukes is a surface syncytial layer covering the parasite, rich in secretory inclusions and bounded externally by a plasma membrane bearing a dense glycocalyx. Important tegumental functions include renewal of the surface plasma membrane and the active uptake of nutrients (Dalton et al., 2004). The combined plasma membrane and its glycocalyx can potentially interact directly with the immune system but few studies have analysed tegument surface proteins. Surface radiolabelling was used to identify seven proteins from 10 to $78 \mathrm{kDa}$ in F. hepatica NEJs, revealing that the profile changed during the first 7-14 days of infection (Lammas et al., 1985). A second labelling study demonstrated variations in surface composition of proteins from 14 to $>200 \mathrm{kDa}$, between NEJ, immature and adult flukes (Dalton and Joyce, 1987) and a protein on the juvenile fluke tegument showing a repetitive sequence has been identified (Trudgett et al., 2000).
Lastly, a detergent extract of $F$. hepatica tegument proteins with undefined composition was shown to suppress the maturation and function of murine bone marrow-derived dendritic cells (Hamilton et al., 2009). Clearly, further definition of the proteins on the tegument surface of the fluke is needed to inform vaccine development.

In contrast, the tegument proteins of the related flukes Schistosoma mansoni (van Balkom et al., 2005; Braschi et al., 2006; Braschi and Wilson, 2006), Schistosoma japonicum (Mulvenna et al., 2010a) and Opisthorchis viverrini (Mulvenna et al., 2010b) have recently been subjected to proteomic analysis. The studies have ranged from the simple compositional analysis of material sloughed off the fluke surface by freeze/thaw/vortexing (van Balkom et al., 2005) to more sophisticated protocols that enrich for tegument membrane proteins using differential extraction (Braschi et al., 2006). Proteins accessible to impermeant probes on live schistosomes have been tagged with biotin to facilitate their recovery and identification (Braschi and Wilson, 2006; Mulvenna et al., 2010a). Finally, live schistosomes have also been subjected to a complementary approach of enzymatic shaving that releases exposed proteins into the medium for recovery and identification (Castro-Borges et al., 2011). Such studies have provided a wealth of information about the surface organisation of the blood dwelling schistosomes and it is notable that two surface-exposed tegument proteins of $S$. mansoni have shown efficacy as vaccines in the mouse model of schistosomiasis (Tran et al., 2006; Cardoso et al., 2008). Here, as the first step towards a molecular definition of the tegument surface, the parasite-host interface, the better to understand the interaction of $F$. hepatica with the immune system, we report the analysis of tegument proteins isolated from the adult fluke.

\section{Materials and methods}

\subsection{Biological material}

Adult flukes were obtained from the bile ducts of cattle at York Abattoir (Anglo Beef Processors Ltd., United Kingdom), situated approximately 1 mile from the University of York laboratory. They were collected into ice-cold RPMI-1640 medium (Invitrogen, Paisley, Scotland) immediately after culling, separated from contaminating blood, mucus and bile by washing extensively in medium, and given a pre-incubation at $37^{\circ} \mathrm{C}$ for $30 \mathrm{~min}$ prior to tegument isolation.

\subsection{RNA isolation and cDNA synthesis for 454 sequencing}

Live flukes in RPMI-1640 medium were homogenised in TRIzol ( $3 \mathrm{ml}$ per worm) (Invitrogen) and $1 \mathrm{ml}$ aliquots stored at $-80^{\circ} \mathrm{C}$. Total RNA was extracted by addition of $200 \mu$ of chloroform per $\mathrm{ml}$ of TRIzol, mixed by inversion for $15 \mathrm{~s}$, incubated at $20^{\circ} \mathrm{C}$ (room temperature; RT) for $3 \mathrm{~min}$, and then centrifuged at $12,000 \mathrm{~g}$ for $5 \mathrm{~min}$ at $4{ }^{\circ} \mathrm{C}$ to separate the phases. The aqueous layer was removed, $250 \mu$ leach of isopropanol and high salt solution $(0.8 \mathrm{M}$ sodium citrate, $1.2 \mathrm{M} \mathrm{NaCl}$ ) were added to precipitate RNA at $-80^{\circ} \mathrm{C}$ overnight. The sample was centrifuged at $12,000 \mathrm{~g}$ for $30 \mathrm{~min}$ at $4{ }^{\circ} \mathrm{C}$ and the resulting pellet washed twice with $70 \%$ ethanol, the supernatant carefully removed and the pellet air dried at RT. The RNA was resuspended in $300 \mu$ of diethyl pyrocarbonate (DEPC)treated water, quantified using a Nanodrop spectrophotometer (Invitrogen) and re-precipitated with $30 \mu \mathrm{l}$ of $3 \mathrm{M}$ sodium acetate, $\mathrm{pH} 7.5,990 \mu \mathrm{l}$ absolute ethanol. Total RNA ( $1 \mu \mathrm{l}$ sample containing $50-500 \mathrm{ng} / \mu \mathrm{l}$ ) was quality-assessed using a Bioanalyser RNA 6000 NanoChip (Agilent, Wokingham, Berks). Polyadenylated RNA was purified from a pool of total RNA derived from three flukes using 
a PolyA purist kit (Ambion, Huntingdon, UK) according to the manufacturer's instructions. Briefly, total RNA was incubated with poly (T) cellulose at $70^{\circ} \mathrm{C}$ for $5 \mathrm{~min}$ and then $1 \mathrm{~h}$ at RT. The cellulose pellet was washed five times and the poly(A) RNA eluted with $400 \mu \mathrm{l}$ of warm $\left(70{ }^{\circ} \mathrm{C}\right) 1 \mathrm{mM}$ sodium citrate, before precipitation with 0.1 vol. of $5 \mathrm{M}$ ammonium actetate, $1 \mu \mathrm{l}$ Glycoblue $(15 \mathrm{mg} / \mathrm{ml}$; Ambion), 2.5 vol. absolute ethanol, at $-80^{\circ} \mathrm{C}$, overnight.

Double-stranded cDNA was made using a SMART PCR cDNA synthesis kit, with PrimeScript reverse transcriptase and an Advantage 2 PCR kit (all from Clontech, Mountain View, CA, USA) to enrich for full length transcripts. A $1 \mu \mathrm{g}$ sample of polyA RNA was added per $10 \mu \mathrm{l}$ reaction and the first strand synthesis allowed to proceed for $1 \mathrm{~h}$ at $37^{\circ} \mathrm{C}$. A $2 \mu \mathrm{l}$ aliquot from this reaction was subjected to long-range PCR for 13 cycles, according to the manufacturer's instructions. The quality of a $5 \mu \mathrm{l}$ aliquot of the resulting cDNA from the $100 \mu \mathrm{l}$ reaction mixture was assessed on a $1.5 \%$ agarose gel before submission to the Genomics Laboratory within the York Technology Facility, for 454 sequencing on the Genome Sequencer FLX platform (Roche, Branford, CT, USA).

\subsection{Tegument preparation by freeze/thaw/vortexing}

The method for isolation of the tegument surface membranes of F. hepatica (Fig. 1) was derived from that used for the blood fluke $S$. mansoni (Braschi et al., 2006), which in turn was based on the freeze/thaw/vortex (FTV) protocol developed earlier (Roberts et al., 1983). Briefly, 20 adult flukes were snap-frozen in liquid $\mathrm{N}_{2}$, then slowly thawed to $4{ }^{\circ} \mathrm{C}$ in $5 \mathrm{ml}$ of ice cold RPMI-1640 medium plus protease inhibitors (Protease inhibitor cocktail, Sigma, Poole, Dorset, UK). The tegument was detached from fluke bodies by $10 \times 1 \mathrm{~s}$ pulses on a vortex mixer and the supernatant recovered by allowing the bodies to settle at $4^{\circ} \mathrm{C}$. The membranes (S2P) were pelleted from this supernatant by centrifugation at $500 \mathrm{~g}$ for $30 \mathrm{~min}$ at $4{ }^{\circ} \mathrm{C}$, leaving a supernatant (S2S) that was recentrifuged at $100,000 \mathrm{~g}, 30 \mathrm{~min}, 4^{\circ} \mathrm{C}$ to produce the cytosolic fraction (S2SS). The residual S2P pellet was washed three times in $40 \mathrm{mM}$ tris(hydroxymethyl)aminomethane (Tris), $\mathrm{pH} 7.4$ at $4{ }^{\circ} \mathrm{C}$, with intervening centrifugations, to remove soluble contaminants. It was then extracted with $100 \mu \mathrm{l} 5 \mathrm{M}$ urea (BDH, VWR International,
Dorset, UK), $2 \mathrm{M}$ thiourea (BDH) in $40 \mathrm{mM}$ Tris, 4\% 3-[(3-Cholamidopropyl)dimethylammonio]-1-propanesulfonate (CHAPS; Sigma), $2 \%$ caprylyl sulfobetaine (SB 3-10; Sigma) to recover membraneassociated proteins (UTCS extract), recentrifuged at $100,000 \mathrm{~g}$, $30 \mathrm{~min}, 4{ }^{\circ} \mathrm{C}$ and the final pellet (FP) solubilised with $50 \mu \mathrm{l}$ of $0.1 \%$ SDS, $1 \%$ Triton X-100 in $100 \mathrm{mM}$ triethylammonium bicarbonate (TEAB) at RT. A protein assay was performed on S2SS using Coomassie Plus Bradford reagent (Thermo Lifescience, Basingstoke, UK). UTCS and FP samples were assayed by separation on a one dimensional (1D) SDS NuPAGE 4-12\% gradient gel (Invitrogen) with 5 and $10 \mu \mathrm{g}$ S2SS as a comparator, stained with Sypro Ruby overnight, imaged with a Molecular FX imager and total protein content estimated by densitometry analysis using Quantity One software (all BioRad, Hemel Hempstead, UK).

\subsection{Adult secreted proteins}

Unlike adult $S$. mansoni, which are reluctant to vomit in vitro, adult $F$. hepatica readily regurgitate their gut contents. A batch of newly collected flukes (washed as described in Section 2.1) was pre-incubated at $37^{\circ} \mathrm{C}$ for $30 \mathrm{~min}$ in a large culture dish to encourage vomiting and diminish contamination from gut contents. This provided a sample of vomitus for MS/MS analysis. The flukes were then washed three times in RPMI-1640 with a minimum of physical handling before transfer to $5 \mathrm{~cm}$ diameter plastic culture dishes for short-term culture; only the paler flukes that had visibly emptied the pigment from their guts were used for this incubation. Groups of six flukes were incubated at $37^{\circ} \mathrm{C}$ for $1 \mathrm{~h}$ to provide total secretions, the experiment being performed three times to provide biological replicates. The supernatant was removed and concentrated at $4{ }^{\circ} \mathrm{C}$ using a $5,000 \mathrm{~mol}$. wt cut-off centrifugation device (Vivaspin, Vivascience, Generon, Maidenhead, UK or Amicon, Millipore, Watford, UK).

\subsection{Electron microscopy}

Immediately prior to UTCS extraction, the detached tegument (S2P) sample was evaluated by transmission electron microscopy (TEM) to determine the nature of the material being subjected to

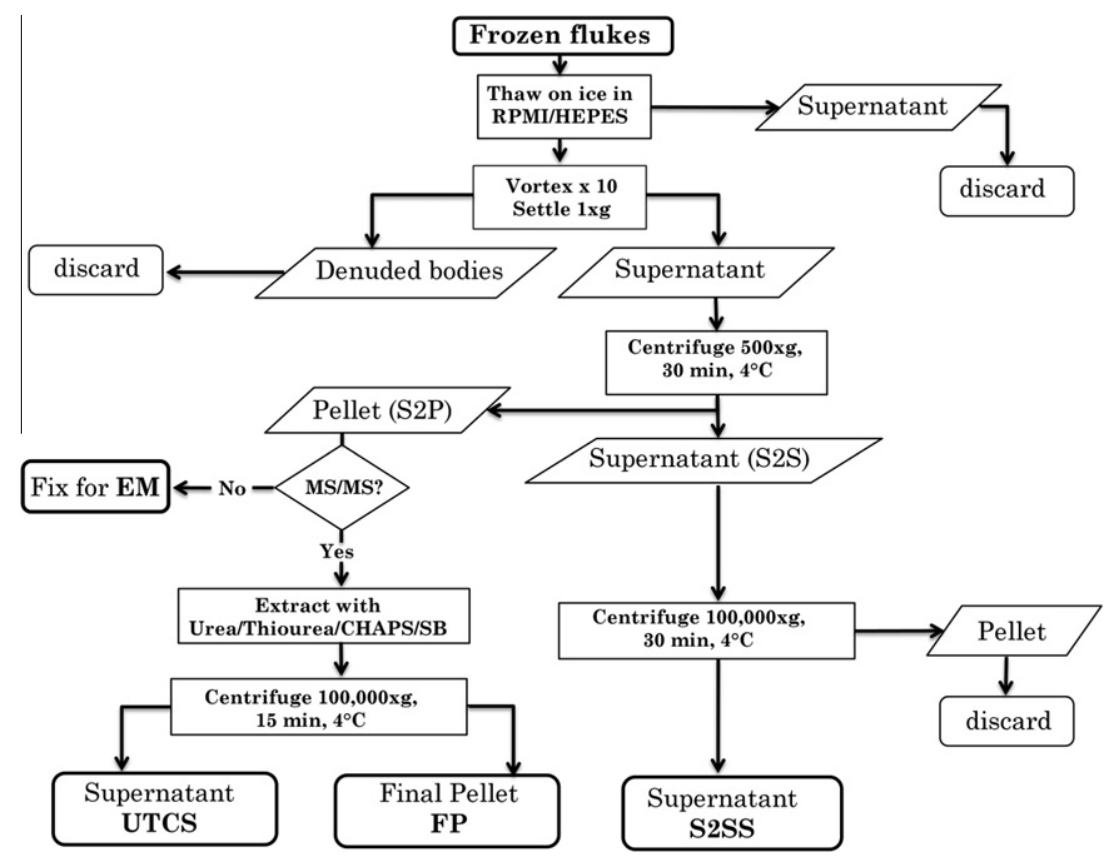

Fig. 1. Flow chart of the tegument isolation and fractionation procedure. 
MS/MS analysis. The pellet was fixed in $2.5 \%$ glutaraldehyde/ $4 \%$ formaldehyde in $0.1 \mathrm{M}$ phosphate buffer, $\mathrm{pH} 7.2$, at $4{ }^{\circ} \mathrm{C}$ overnight. Flukes from the secretion experiment were similarly fixed, cut into 1-2 mm cubes after $30 \mathrm{~min}$ in fixative and then post-fixed in 1\% aqueous osmium tetroxide at $4{ }^{\circ} \mathrm{C}$ overnight. All samples were washed three times in $0.1 \mathrm{M}$ phosphate buffer, $\mathrm{pH} 7.2$, at $4{ }^{\circ} \mathrm{C}$, then post-fixed in $1 \%$ aqueous osmium tetroxide at RT for $1.5 \mathrm{~h}$. After three washes in distilled water, specimens were dehydrated in a graded series of acetones and embedded in Spurr resin. Thin sections (80-100 nm) were cut on an Ultracut UCT (Leica, Milton Keynes, UK) and collected on 400-mesh hexagonal copper grids, then stained with $1 \%$ uranyl acetate in $50 \%$ ethanol and lead citrate (Reynolds, 1963). Sections were imaged on a Tecnai G2 BioTWIN operating at $120 \mathrm{kV}$ (FEI, Hillsboro, Oregon).

\subsection{Sample preparation and liquid chromatography}

Aliquots containing $50 \mu \mathrm{g}$ of S2SS, $20 \mu \mathrm{g}$ of UTCS and $20 \mu \mathrm{g}$ S2P protein, respectively, were subjected to in-solution digestion. Briefly, each protein aliquot was diluted in $100 \mu \mathrm{l}$ of $0.4 \mathrm{M} \mathrm{TEAB}$ and denatured in the presence of $0.1 \%$ SDS. Cysteine residues were reduced by adding $1 \mathrm{mM}$ tris-(2-carboxyethyl) phosphine (TCEP) during incubation at $65^{\circ} \mathrm{C}$ for $30 \mathrm{~min}$. Alkylation was then performed by addition of $10 \mathrm{mM}$ methyl methane-thiosulfonate (MMTS) for $1 \mathrm{~h}$ in the dark at RT. Trypsin (Sequencing Grade, Promega, Southhampton, UK) was then added at a 1:20 (enzyme:substrate) ratio and the final volume of the in-solution digestion adjusted to $200 \mu \mathrm{l}$ with $0.4 \mathrm{M}$ TEAB. Digestion was allowed to proceed overnight at $37^{\circ} \mathrm{C}$. The digested samples were centrifuged at $10,000 \mathrm{~g}$ for $3 \mathrm{~min}$, the supernatant concentrated using a SpeedVac (Thermo Scientific, Basingstoke, UK) and redissolved in $500 \mu \mathrm{l}$ of loading solution $\left(10 \mathrm{mM} \mathrm{KH}_{2} \mathrm{PO}_{4}\right.$ in $25 \%$ acetonitrile $(\mathrm{ACN}), \mathrm{pH}$ 3.0). Two clean-up steps were used. For the first step, to remove SDS and excess reducing and alkylating reagents, the sample was loaded onto a cation exchange cartridge-system (P/N4326747, Applied Biosystems, Framingham, USA), and eluted with loading solution plus $350 \mathrm{mM} \mathrm{KCl}$ ( $\mathrm{pH} 3.0$ ) according to the manufacturer's instructions. For the second step, to remove salts, the sample was concentrated to dryness using the SpeedVac, resuspended in $1.0 \mathrm{ml} 0.1 \%$ trifluoroacetic acid (TFA), and loaded onto a C18 column (Strata C18-E, $55 \mu \mathrm{m}, 70 \AA$ A , Phenomenex, Macclesfield, UK). Bound peptides were eluted twice in $250 \mu \mathrm{l}$ of $50 \% \mathrm{ACN} / 0.1 \%$ TFA, concentrated to dryness and resuspended in $20 \mu \mathrm{l} 0.1 \%$ TFA. A $3 \mu \mathrm{l}$ aliquot was loaded onto an UltiMate LC system (Dionex, Camberley, UK) equipped with a polystyrene-divinylbenzene (PS-DVB) monolithic column $(200 \mu \mathrm{m}$ internal diameter $\times 5 \mathrm{~cm})$. Peptides were eluted over a linear gradient of $3-51 \%(v / v)$ ACN at a flow rate of $3 \mu \mathrm{l} / \mathrm{min}$, with $0.1 \%$ heptafluorobutyric acid as the counter ion throughout, monitoring UV absorbance at $214 \mathrm{~nm}$. A Probot microfraction collector (Dionex) was used to collect 6-s fractions onto a prespotted anchor chip containing 4-hydroxy- $\alpha$ cyano-cinnamic acid (Bruker Daltonics, Bremen, Germany).

Samples of vomitus and secretion supernatants were subjected to in-solution digestion and then processed for LC-MS/MS, exactly as described above for the tegument fractions.

\subsection{Tandem MS and database searching}

Positive-ion MALDI-TOF-MS spectra were obtained using an Ultraflex III (Bruker Daltonics, Coventry, UK) in reflectron mode, equipped with a Nd:YAG smart beam laser. MS spectra were acquired over a mass range of $m / z 720-4000$ and calibrated externally against an adjacent prespotted anchor chip containing nine mass standards (Bruker Daltonics). Monoisotopic masses were obtained using a SNAP averaging algorithm (C 4.9384, N 1.3577, O $1.4773, \mathrm{~S} 0.0417, \mathrm{H} 7.7583$ ) and a S/N threshold of 3.
For each spot, the 10 strongest peaks, with a $S / N$ ratio $>15$, were selected for MS/MS fragmentation. Where similar peaks of less than $100 \mathrm{ppm}$ (ppm) mass difference were observed, within six fractions, only the most intense were fragmented. Peaks present in over $70 \%$ of the fractions were considered to be background and were not selected for fragmentation. Fragmentation was performed in LIFT mode without the introduction of a collision gas. The default calibration was used for MS/MS spectra, which were baseline-subtracted and smoothed (Savitsky-Golay, width $0.15 \mathrm{~m} /$ $z$, cycles 4); monoisotopic peak detection used the SNAP averaging algorithm with a minimum $\mathrm{S} / \mathrm{N}$ threshold of 1 . Bruker Flex Analysis software was used to perform the spectral processing and peak list generation for both the MS and MS/MS spectra.

Data were searched using Mascot software (version 2.1, Matrix Science, London, UK) through the Bruker BioTools interface (version 3.2). The significance threshold of the Mascot output was adjusted to provide an approximately $1 \%$ false discovery rate by searching of a Mascot-generated decoy database, and results filtered with an expect value $<0.05$. Databases searched were: (i) National Center for Biological Information non-redundant (NCBInr) [http://www.ncbi.nlm.nih.gov/protein]; (ii) FhA, compiled from expressed sequence tags (ESTs) deposited on the Wellcome Trust Sanger Institute (WTSI) ftp site [ftp://ftp.sanger.ac.uk/pub/pathogens/Fasciola]; (iii) $\mathrm{FhB}$, an in-house database compiled from $\sim 150,000$ reads from the 454 sequencer; (iv) FhC, the new transcript database established recently (Young et al., 2010). FhB was annotated automatically against Uniprot, NCBInr and S. mansoni gene predictions (www.GeneDB.org), followed by manual inspection to select the most credible annotation. FhA was annotated automatically against the $S$. mansoni gene predictions and FhC by its originators. The FhB database is available on request from R.A. Wilson (raw3@york.ac.uk).

The identity of $F$. hepatica proteins revealed by Mascot searching was first determined using the FhB database. The list was then augmented by adding new identities revealed by a search using FhA, host proteins and full-length $F$. hepatica cDNAs at NCBInr, and finally using the FhC database when this became available. The exponentially modified protein abundance index (emPAI; Ishihama et al., 2005), generated by Mascot for each protein identity, was used as an approximate guide to its abundance in all samples examined. The emPAI is based on the number of peptides actually observed, relative to the number observable per protein. All $F$. hepatica-specific proteins identified by MS/MS that lacked homology were subjected to a conserved domain (CDD) search for domain structure (NCBI). They were also interrogated using SignalP (http://www.cbs.dtu.dk/services/SignalP/) to detect leader sequences, and HMMTOP (http://www.enzim.hu/hmmtop/) for membrane spanning regions, enabling some unknown proteins to be assigned to secreted and/or membrane categories.

\section{Results}

\subsection{Analysis of transcript data}

The 353 adult $F$. hepatica cDNA sequences deposited in the NCBInr database at the end of 2009, with much redundancy, do not form an adequate database to undertake tegument proteomics. The additional single-pass ESTs from adult flukes available at the Wellcome Trust Sanger Institute (WTSI) ftp site improved coverage of the transcriptome, compiling into 1,064 contigs and 3,009 singlets (termed here the FhA database). Further to this we obtained 3,923 contigs (FhB database) from $\sim 150,000$ reads generated by 454 sequencing of adult fluke cDNA. We later added the 14,424 adult fluke FhC contigs and a larger number of singlets, thus achieving a total in excess of 20,000 assembled contigs for Mascot 
searching of MS/MS spectra. Inevitably there is overlap in content between the different sequence sources, but collectively they should provide a good representation of the adult transcriptome. From previous work on the proteome of S. mansoni we compiled a list of known tegument proteins in that parasite, which comprised seven membrane enzymes, 15 membrane-spanning transporters, nine transport-associated ATPases, five surface defence proteins, 14 proteins from the exocytosis pathway, eight membrane-associated GTPases, 13 membrane structural proteins, and five surface proteins with no homology (Braschi et al., 2006; Castro-Borges et al., 2011, and our unpublished data). The three Fh databases were then interrogated using this list to find any $F$. hepatica orthologues (Table 1). Remarkably, many proteins previously identified in the $S$. mansoni tegument membranes were represented by orthologues encoding sequences in the $F$. hepatica transcriptome. All seven of the membrane enzymes and 15 transporters were detected, together with all nine associated ATPases. Three of five surface defence proteins, 13 of the 13 exo/endo cytosis pathway proteins, all eight of the S. mansoni GTPases and 10 of the 13 membrane structural proteins were found. Additionally, two trematode-specific tegument proteins of unknown function, Sm200 and Low Molecular Weight Protein (LMWP), were represented in the $F$. hepatica transcriptome.

\subsection{Morphology of the tegument pellet}

To facilitate interpretation of tegument protein composition, a tegument pellet was subjected to TEM, prior to the UTCS extraction step. It should be noted that the material had been subjected to freeze/thaw/vortexing before processing for electron microscopy so that considerable distortion of structure was inevitable. Most areas of the pellet contained sheets of membrane that convincingly approximated in appearance to detached tegument surface (Fig. 2A and B). However, small membranous vesicles (Fig. 2A) were also present, as well as more densely stained spherical inclusions (Fig. 2B). We interpret the more granular of these as mitochondrial remains while the darker inclusions probably represent secretory vesicles. The pellet was not homogeneous in composition throughout, aggregates of free $F$. hepatica sperm being apparent in at least one area (Fig. 2C). These can be clearly identified by the long double flagellum of the tail in both longitudinal and cross-section, as well as the microtubule-demarcated head region. A single $F$. hepatica egg was also located in one section, clearly identifiable by the tanned protein egg shell, but lacking internal features due to plasmolysis during processing (Fig. 2D).

\subsection{Proteomic analysis of S2SS, UTCS and FP fractions}

The scheme of sample processing after tegument detachment by FTV was intended to deplete the sample, first of cytosolic components and then of proteins more strongly associated with the plasma membrane, leaving a final pellet enriched in tightly-bound tegument surface proteins. A total of 229 proteins was identified from the various fractions, distributed 100, 125 and 88 between the S2SS, UTCS and FP fractions, respectively (Supplementary Tables S1-S6). A measure of the effectiveness of the differential extraction protocol is provided by the number of unique identities in each fraction (58, 45 and 38, respectively), representing 57\%, $35 \%$ and $44 \%$ of each sub-total. As further evidence for the success of the partitioning protocol, 19 proteins $(8 \%)$ were shared between all fractions, whilst only five were present in the first S2SS and last FP fractions but not in the intermediate UTCS fraction. The smallest number of identities in the FP results from the prior removal of the bulk of proteins by the extraction process, and this is reflected in the emPAI totals for each: S2SS, 66.5; UTCS, 48.2; FP, 26.9 (repre- senting $47 \%$, $34 \%$ and $19 \%$ of the notional total, respectively; Supplementary Tables S2-S6).

A functional annotation was provided for all but 38 constituents, of which four (termed Fasciola-specific, membrane helix) could be assigned to the membrane category and six (termed Fasciola-specific, secreted) to the secretory pathway on the basis of the CDD/SignalP/HMMTOP searches (Table 2), leaving 28 unassigned proteins that were $F$. hepatica or trematode-specific (Supplementary Tables S1-S6). The differing compositions of the three fractions was also evident when classified by function (Fig. 3; Table 2; Supplementary Table S1) and plotted by emPAI score to take account of approximate abundance. The major constituents of the soluble (cytosolic) S2SS fraction, were in descending percentage order: cytoskeleton (18), defence (12), energy metabolism e.g. glycolytic enzymes (12), unknown function (11), carrier proteins (11), calcium-binding (11), chaperones (7), proteases and inhibitors (7), mitochondria (3), miscellaneous (3), membrane (2), secretory pathway (2) and nuclear (1). UTCS extraction of the washed (i.e. insoluble) membrane pellet increased representation of membrane and secreted proteins to $15 \%$ and $6 \%$, respectively, but mitochondrial proteins also increased to $23 \%$ and nuclear proteins to $10 \%$ (Fig. 3; Supplementary Table S1). Proportionally, other categories such as defence, energy, calcium binding, protease and carrier had all decreased, although cytoskeleton remained high at $13 \%$. This presumably reflects the anchoring of many cytoskeletal proteins to membranes and organelles.

Similar trends were also seen in the composition of the FP fraction with mitochondrial, membrane, secretory pathway and nuclear proteins representing 24\%, $14 \%, 16 \%$ and $10 \%$, respectively (Fig. 3; Supplementary Table S1). The cytoskeletal and calciumbinding proteins as well as chaperones now each represented 2$4 \%$ of the FP, whilst carrier proteins and proteases were virtually undetectable although one ferritin sequence was identified (Supplementary Table S1). Note that histone $\mathrm{H} 4$ is represented by a small sequence fragment, not a full coding sequence to which the peptide hits gave almost full coverage, distorting the emPAI (6.17). As histones are in equimolar ratios in the histone core of the nucleus (Chung et al., 1978), the values for H4 were therefore replaced by the mean of the emPAIs for all other histones (0.32). Overall, the fractionation protocol succeeded in enriching for membrane and secretory pathway proteins (minus proteases and inhibitors), their proportions increasing from 2 to 15 to $16 \%$ and 2 to 6 to $14 \%$, respectively, from S2SS to UTCS to FP. In turn the soluble glycolytic enzymes (energy category) were reduced from 12 to 6 to $8 \%$ and gut proteases from 7 to 0 to $0 \%$, respectively. The mitochondrial proteins (3\%, $23 \%$ and $24 \%$ ) were also highly enriched constituents in the FP.

The specific constituents of each functional category provide indicators to biological processes occurring in the tegument. Here we focus on the membrane and secreted proteins likely to be uniquely involved in tegument function. We note only that the vast majority of proteins identified, particularly in the S2SS fraction, are a cross section of the fluke cytosol and cytoskeleton, and details are given in Supplementary Tables S1-S6. The same is true of the mitochondrial and nuclear proteins that were enriched by the FTV method and subsequent extraction steps; details of identities obtained can be found in Supplementary Tables S1-S6.

\subsubsection{Membrane-associated category}

Of the 24 membrane and membrane-associated proteins identified, three appear to be distinct annexins, two of them (FhB02550 and FhB00592) major constituents as judged by their emPAI scores of 1.11 and 2.86, respectively (Table 2). A single tetraspanin, (orthologous to Smp_152990 that is distinct from TSP1 or TSP2) was identified as well as three ferlins, all of which can be classified as membrane structural proteins. Three transport proteins, two of 
Table 1

Putative orthologues of Schistosoma mansoni tegument proteins identified in the Fasciola hepatica transcriptome.

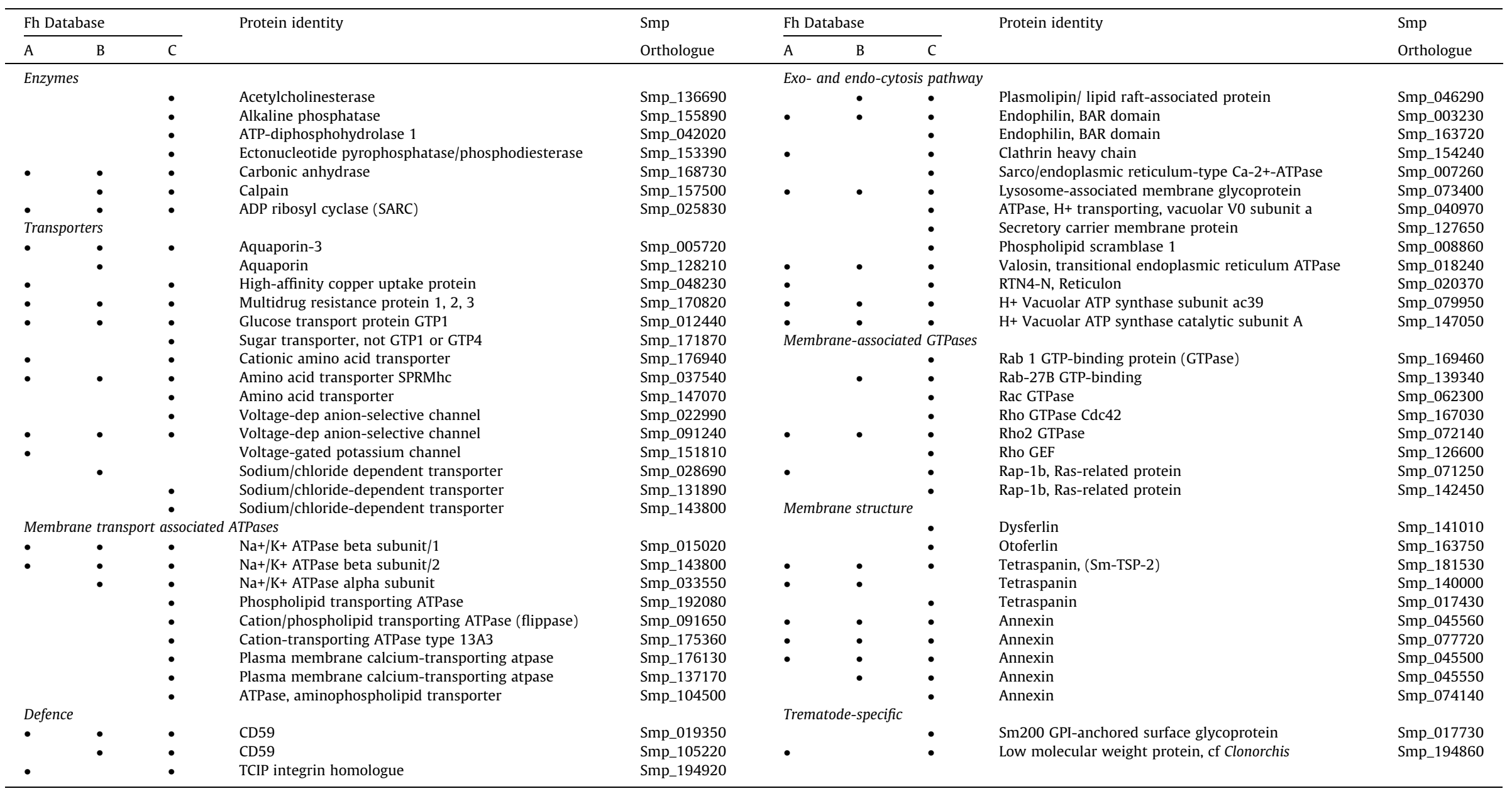




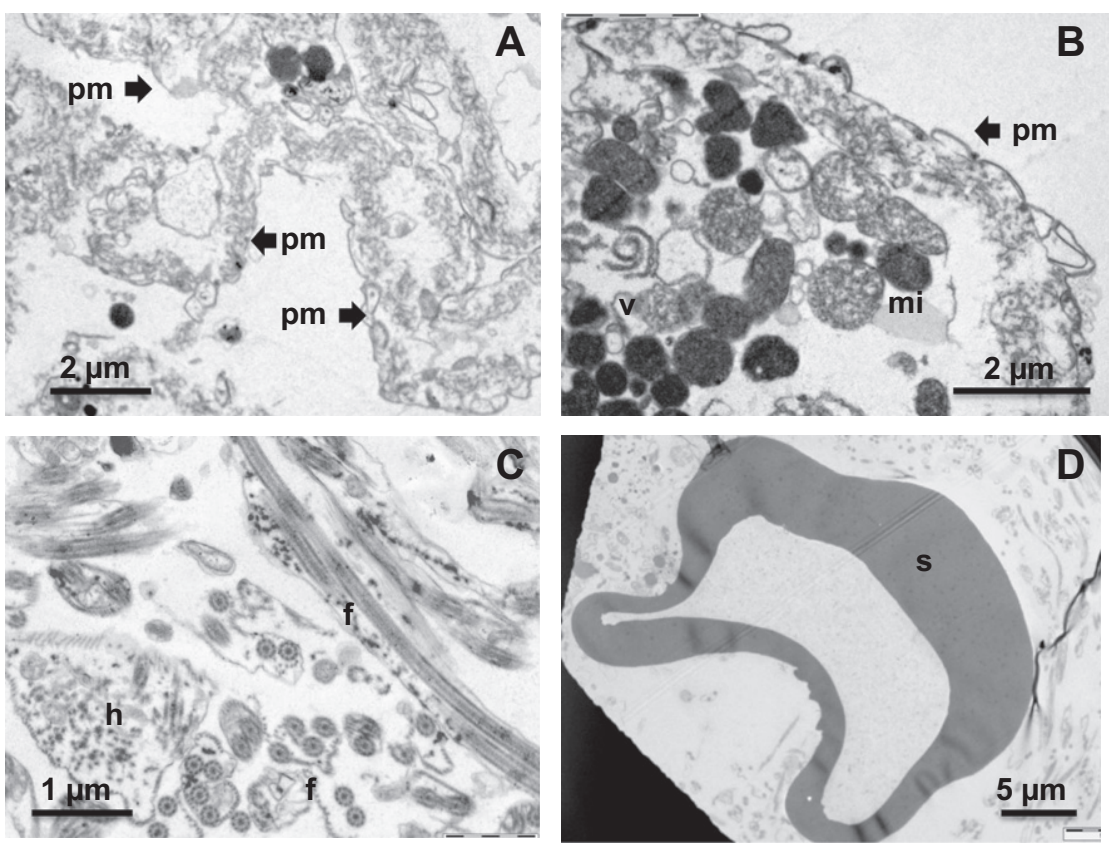

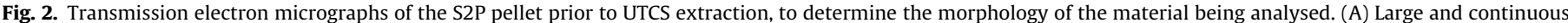

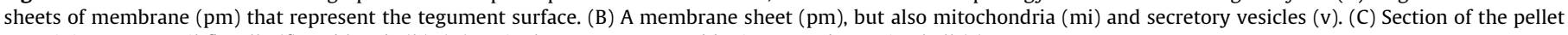
containing sperm tail flagella (f) and heads (h). (D) A single egg, represented by its tanned protein shell (s).

them anion-selective channels and the third a glucose transporter, were detected plus three membrane enzymes, a carbonic anhydrase and two calpain proteases. A CD59 orthologue was identified, which in humans is an inhibitor of complement fixation. Although no receptors were found, a single GTPase and five other small GTPase-associated proteins all point to the occurrence of cell signalling processes at the tegument surface. Four $F$. hepatica-specific proteins, all in the FP, were predicted by HMMTOP to encode 1-3 membrane-spanning regions so were assigned to the membrane category (Table 2 ).

\subsubsection{Secretory protein category}

A total of 21 proteins was assigned to the secreted/secretory pathway, exclusive of putative gut proteases and a Kunitz-type protease inhibitor, which were present in the S2SS fraction and are treated separately below. Nineteen of the 21 proteins were

Table 2

Membrane, membrane-associated and secreted proteins identified in cytosolic (S2SS), pellet extract (UTCS) and final pellet (FP) fractions of tegument.

\begin{tabular}{|c|c|c|c|c|c|c|c|c|c|}
\hline Database & Protein ID & $\begin{array}{l}\text { emPAI } \\
\text { S2SS }\end{array}$ & $\begin{array}{l}\text { emPAI } \\
\text { UTCS }\end{array}$ & $\begin{array}{l}\text { emPAI } \\
\text { FP }\end{array}$ & Database & Protein ID & $\begin{array}{l}\text { emPAI } \\
\text { s2SS }\end{array}$ & $\begin{array}{l}\text { emPAI } \\
\text { UTCS }\end{array}$ & $\begin{array}{l}\text { emPAI } \\
\text { FP }\end{array}$ \\
\hline & Membrane associated & & & & FhA00116 & C-type lectin domain, secreted C & & & 0.17 \\
\hline FhB01398 & Annexin a & & 0.21 & & FhC02107 & Galectin domain & & 0.07 & 0.07 \\
\hline FhB02550 & Annexin b & 1.11 & 0.93 & & FhC02219 & CUB (cubulin) domain & & & 0.31 \\
\hline FhB00592 & Annexin c & 0.20 & 2.86 & 1.34 & FhC06044 & CUB (cubulin) domain & & & 0.14 \\
\hline FhB00705 & Tetraspanin & & 0.28 & 0.30 & FhC06620 & CUB (cubulin) domain & & & 0.15 \\
\hline FhC14169 & Otoferlin A & & & 0.25 & FhA03239 & LMWP cf. Clonorchis & & & 0.1 \\
\hline FhC14498 & Dysferlin & & 0.19 & 0.28 & FhB00114 & SmKK7-like & 0.77 & & \\
\hline c48411 & Otoferlin B & & & 0.37 & FhC00742 & von Willebrand factor A domain & & 0.36 & \\
\hline FhB03799 & Voltage-dep anion-selective channel & & 0.12 & 0.12 & FhC05840 & Vacuolar protein ATPase & & & 0.06 \\
\hline FhC06452 & Calcium-activated chloride channel & & 0.14 & & FhB01127 & Endophilin B1 & 0.92 & 0.48 & 0.51 \\
\hline FhC00666 & Glucose transporter & & & 0.09 & FhB00788 & Translocon-associated protein delta & & 0.28 & \\
\hline FhB00925 & Carbonic anhydrase & & 0.29 & 0.14 & FhB02015 & Ribophorin I, oligosaccharyltransferase & & 0.17 & \\
\hline FhB00712 & Calpain A & & 0.24 & & FhC00286 & Oligosaccharyl-transferase & & 0.09 & \\
\hline FhB01987 & Calpain B & & 0.19 & & FhB00004 & Fasciola-specific, secreted & & & 0.87 \\
\hline FhA04073 & CD59 orthologue & & & 0.22 & FhC04266 & Fasciola-specific, secreted & & & 0.45 \\
\hline FhA03206 & Rho2 GTPase, membrane signalling & & 0.24 & & FhB02167 & Fasciola-specific, secreted & & 0.18 & 0.41 \\
\hline FhC06056 & Rho GTP-binding protein & & 0.22 & & FhB01808 & Fasciola-specific, secreted & & 0.25 & 0.59 \\
\hline FhC02604 & Rab5 & & 0.2 & & FhC00442 & Fasciola-specific, secreted & & 0.37 & \\
\hline FhC01017 & Rab-2,4,14, & & 0.25 & & FhC05339 & Fasciola-specific, secreted & & 0.23 & \\
\hline FhC05214 & Rab 11B & & 0.08 & & & Proteases and inhibitors & & & \\
\hline FhC00074 & Rab GDP-dissociation inhibitor & 0.09 & & & FhC02704 & Kunitz-type proteinase inhibitor & 2.39 & & \\
\hline FhB00010 & Fasciola specific, membrane helix & & 0.12 & 0.12 & FhB00269 & Cathepsin L (Clade 1) & 0.14 & & \\
\hline FhB01238 & Fasciola specific, membrane helix & & & 0.17 & FhB01160 & Cathepsin L (Clade 2) & 0.17 & & \\
\hline FhB01787 & Fasciola specific, membrane helix & & & 0.45 & FhB03790 & Cathepsin L (unclassified) & 1.27 & & \\
\hline \multirow[t]{2}{*}{ FhC00749 } & Fasciola specific, membrane helix & & & 0.11 & FhB01159 & Leucyl aminopeptidase & 0.51 & & \\
\hline & Secretory pathway & & & & FhB02190 & Cathepsin A & & 0.07 & \\
\hline FhB00578 & C-type lectin domain, secreted A & & 0.16 & & FhB01026 & DJ-1 protease (park-7) & 0.26 & & \\
\hline FhB01221 & C-type lectin domain, secreted B & & 0.09 & 0.09 & & & & & \\
\hline
\end{tabular}



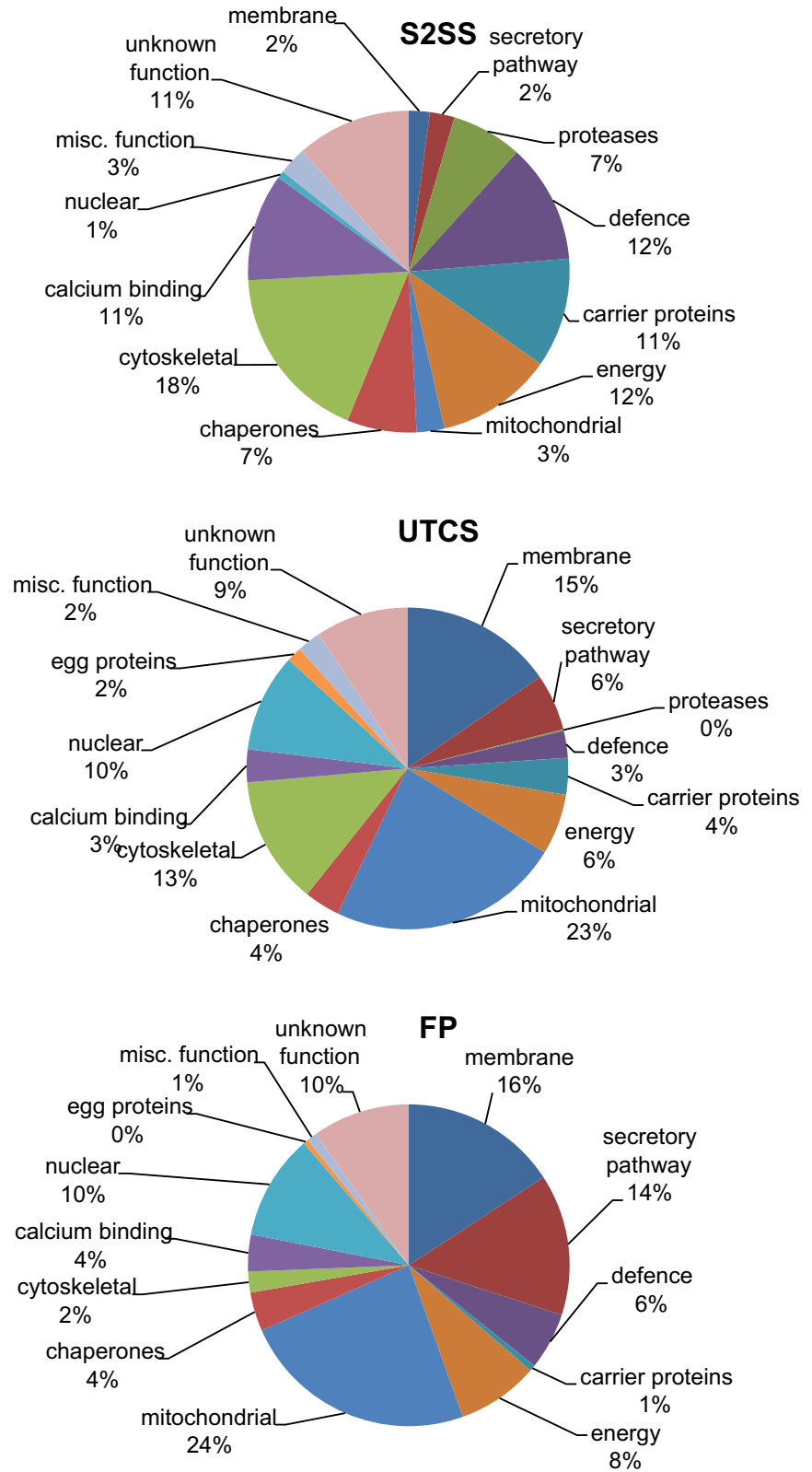

Fig. 3. Pie chart showing the percentage distribution of proteins identified in the cytosolic fraction (S2SS) (A), extract supernatant (UTCS) (B) and final pellet (FP) (C) preparations on the basis of the exponentially modified Protein Abundance Index (emPAI), classified by biological function.

present in the UTCS fraction or the FP. Notable members were four lectins, three with a C-type and one with a galectin domain. In addition three distinct proteins with a cubulin (CUB) domain were identified. A protein containing both anti-alpha trypsin inhibitor and von Willebrand factor type A domains was detected together with two putative $F$. hepatica orthologues of secreted proteins in other trematodes, the proposed potassium channel blocker SmKK7 and the LMWP of Clonorchis. Five proteins associated with the protein export pathway were identified, comprising a vacuolar ATPase, an endophilin and three components of the endoplasmic reticulum/Golgi apparatus (two glycosyltransferases and a translocon-associated protein delta). Finally, six $F$. hepatica-specific proteins encoded a signal peptide but no transmembrane regions, so were assigned to the secretory pathway.

The presence of known gut proteases in the S2SS and UTCS but not the FP fraction indicates some contamination of the tegument
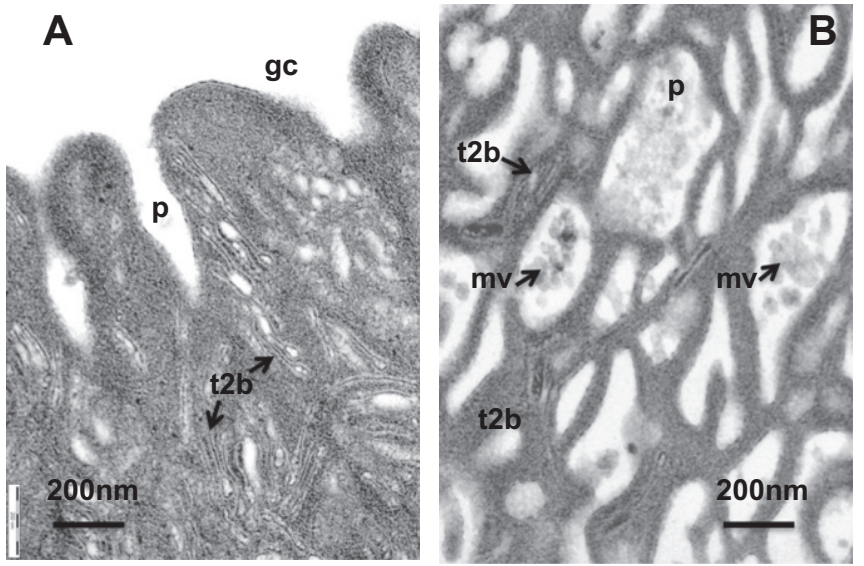

Fig. 4. Transmission electron micrographs of the tegument surface of flukes before (A), and after (B) incubation in RPMI-1640 medium to collect tegument secretions. In the pre-incubation fluke the tegument appears normal with surface pits (p), type 2 secretory vesicles ( $\mathrm{t} 2 \mathrm{~b}$ ) in the cytoplasm and a surface glycocalyx (gc). Postincubation (oblique section), the type 2 secretory vesicles (t2b) are still abundant but the surface pits (p) now contain microvesicles ( $\mathrm{mv}$ ) that may represent leakage of proteins from the cytosol.

preparation (Table 2). Cathepsin L isoforms and the Kunitz-type protease inhibitor were particularly prominent, the latter being by far the most abundant constituent of the S2SS fraction. Mitochondrial proteins were strongly represented in the UTCS fraction but sufficient diagnostic proteins remained after chaotropic/detergent treatment of the tegument preparation for them to constitute the major component of the FP fraction (emPAI total of 6.54; Supplementary Table S1). Motor proteins such as actins, tubulins and dyneins were abundant in the S2SS and UTCS fractions but virtually absent from FP, so very likely extracted by the treatment; in addition to being tegument constituents, these proteins may also derive from the sperm tails visible in the pellet subjected to TEM (Fig. 2; Supplementary Table S1). The nuclear proteins, represented by histones, and ribosomal proteins involved in protein synthesis were not, in contrast, extracted by UTCS treatment and therefore remained in the $\mathrm{FP}$, presumably originating in the sperm heads detected by electron microscopy (Fig. 2).

\subsection{Morphology of flukes after in vitro incubation}

We fixed flukes ex vivo before culture and at the end of the in vitro culture period, for ultrastructural examination. A clear distinction was visible between the two samples. Numerous type 2 disc-shaped bodies were present in the tegument cytoplasm of the ex-vivo flukes, the surface plasma membrane was intact and the external glycocalyx was visible (Fig. 4A). An oblique section through the surface of an in vitro fluke again revealed the type 2 vesicles and an apparently intact surface, but aggregations of small "vesicles" could be seen in some of the surface pits (Fig. 4B). We interpret these vesicles as evidence for the leakage of cytoplasm into the pits, indicating some damage to the plasma membrane. Whilst not extensive, such leakage would have an impact on the composition of tegument secretions detected by proteomic analysis.

\subsection{Proteomic analysis of secretion samples}

Initial observations described above revealed that the adult flukes readily produced abundant vomitus from the gut, containing large quantities of protein (mostly cathepsins) that effectively swamped any possible contribution from the tegument secretions to the culture medium. Therefore, we attempted to "wash-out" the 
Table 3

Proteins identified in vomitus and secretion (SECR.) preparations.

\begin{tabular}{|c|c|c|c|c|c|c|c|}
\hline Database & Identity & VOMITUS & SECR. & Database & Identity & VOMITUS & SECR. \\
\hline & Membrane/membrane-associated & & & & Carrier proteins & & \\
\hline FhB00925 & Carbonic anhydrase & & 0.15 & FhB01065 & NPC- 2 cholesterol transporter & 0.45 & \\
\hline FhB01398 & Annexin & & 0.11 & FhB03724 & NPC-2 cholesterol transporter & 0.4 & 0.46 \\
\hline FhB01618 & Annexin A13 & & 1.02 & FhB00163 & Ferritin & & 0.4 \\
\hline FhB02550 & Annexin B3 & & 0.44 & gi47115698 & Fatty acid binding protein Fh15 & & 1.69 \\
\hline FhB00703 & Tetraspanin (fragment) & & 0.27 & FhB00042 & Myoglobin 1 & 0.12 & 0.14 \\
\hline FhB00083 & Phospholipase A & 0.47 & 0.34 & FhC00255 & Myoglobin & 0.34 & 0.39 \\
\hline FhB00054 & Phospholipase D & 0.07 & & FhB00323 & Haemoglobin F2 & 0.32 & 0.37 \\
\hline \multirow[t]{2}{*}{ FhC06858 } & ATP binding casette protein (peroxysomal) & & 0.09 & & Energy, incl mitochondria & & \\
\hline & Secretory & & & FhB00376 & Hexokinase & & 0.08 \\
\hline FhC01779 & Von Willebrand factor & & 0.05 & FhB00113 & Fructose-bisphosphate aldolase & 0.09 & 0.22 \\
\hline FhC00347 & Nucleoside diphosphate kinase (sig pep) & & 0.29 & FhB00282 & Triose-phosphate isomerase & & 0.15 \\
\hline FhC02704 & Kunitz type protease inhibitor & 2.37 & 0.57 & FhB00588 & Enolase & & 0.34 \\
\hline FhB01959 & Serine protease inhibitor (serpin) & & 0.18 & FhB01525 & Phosphoenolpyruvate carboxykinase 2 & & 0.11 \\
\hline \multirow[t]{2}{*}{ FhB00284 } & Phospholipase B, lysosomal & 0.07 & 0.17 & FhB01995 & NADP-dependent malic enzyme & & 0.41 \\
\hline & Hydrolases & & & FhB00596 & ATP synthase alpha subunit mitochondrial & & 0.11 \\
\hline FhB02186 & Xaa-Pro dipeptidase/prolidase & 0.18 & 0.2 & FhB03623 & Short chain/retinal dehydrogenase & & 0.35 \\
\hline FhB02190 & Carboxypeptidase A & & 0.08 & & Chaperones & & \\
\hline FhB00869 & Cathepsin B & 0.29 & & FhB00008 & $90 \mathrm{kDa}$ heat shock protein & & 0.12 \\
\hline FhB00066 & Cathepsin B & 0.1 & & FhB00129 & Heat shock protein 70 & & 0.68 \\
\hline FhB03844 & Cathepsin B & & 0.15 & FhB00240 & 14-3-3 epsilon & & 0.11 \\
\hline FhC06004 & Cathepsin B1 & 0.11 & & FhB03741 & Peptidyl-prolyl cis-trans isomerase & & 0.5 \\
\hline FhB00106 & Legumain-1/Asparaginyl endopeptidase & 0.09 & 0.1 & FhB01298 & Ubiquitin_L40 precursor & & 0.27 \\
\hline FhB00127 & Leucine amino peptidase & 0.14 & & & Cytoskeletal & & 1.68 \\
\hline FhB00297 & Dipeptidyl-peptidase (lysosomal) & 0.09 & 0.1 & FhB00085 & Actin 2 & & 0.11 \\
\hline FhB00269 & Procathepsin L (Clade 1) & 0.14 & & FhB01516 & Calponin (myophilin) & 0.32 & 0.36 \\
\hline FhC11819 & Cathepsin L (Clade 1) & 0.38 & 0.13 & FhB02827 & Fimbrin & 0.19 & 0.22 \\
\hline FhB03688 & Cathepsin L (Clade 5) & & 0.28 & FhC00899 & Myosin light chain & & 0.27 \\
\hline FhB03790 & Cathepsin L (Unclassified) & & 0.35 & & Ca binding & & \\
\hline FhB03693 & Cathepsin L (Clade 1) & & 0.34 & FhB00790 & Calmodulin-like protein 2 (CaM2) & & 0.27 \\
\hline FhB03882 & Cathepsin L (Unclassified) & & 1.06 & FhB01383 & Calcium-binding protein, $22.6 \mathrm{kDa}$ & & 0.13 \\
\hline FhC13112 & Cathepsin L (Clade 1 or 5 ) & 0.54 & & FhC01433 & EF hand calcium binding protein & & 0.54 \\
\hline FhC15174 & Cathepsin L (Clade 2) & 0.4 & & & Host proteins & & \\
\hline FhB03827 & Cathepsin L (Clade 5) & 0.45 & & gi|4063715 & Immunoglobulin a heavy chain (Bos taurus) & 0.09 & 0.1 \\
\hline FhB03907 & Cathepsin L (Clade 5) & 0.18 & & gi|27819608 & Haemoglobin b subunit (Bos taurus) & 0.31 & 0.84 \\
\hline FhB03910 & Cathepsin L (Unclassified) & 1.28 & 0.59 & gi|576142 & Haemoglobin a subunit (Bos taurus) & 0.34 & 0.38 \\
\hline \multirow[t]{2}{*}{ Irc44928 } & Aminoacylase & & 0.37 & gi|30794280 & Albumin (Bos taurus) & 0.07 & \\
\hline & Defence & & & & Miscellaneous function & & \\
\hline FhB00093 & Thioredoxin-related protein 14 & 0.18 & & FhC00663 & Programmed cell death protein 6 & & 0.28 \\
\hline FhB00158 & Thioredoxin peroxidase & 0.72 & 0.85 & FhC01381 & Programmed cell death 6-interacting protein & & 0.06 \\
\hline FhB00203 & Glutathione $S$-transferase $28 \mathrm{kDa}$. & & 0.18 & & No function attributable & & \\
\hline FhB00340 & Glutathione S-transferase $26 \mathrm{kDa}$ & & 0.17 & FhB03836 & Fasciola specific & 1.68 & \\
\hline FhB01082 & Glutathione dehydrogenase & & 0.12 & FhB02185 & Fasciola specific & & 0.68 \\
\hline \multirow[t]{2}{*}{ gi157887771 } & Thioredoxin-glutathione reductase & & 0.08 & FhC05121 & Fasciola specific & & 0.18 \\
\hline & & & & c52295 & Fasciola specific & 0.55 & \\
\hline
\end{tabular}

gut contents before collecting the secretions. After recovery from bovine livers, transport to the laboratory and extensive washing, a 30-min pre-incubation step was incorporated in the protocol to facilitate expulsion of the gut contents. This released vomitus was analysed by MS/MS to provide a baseline reference against which to detect potential tegument proteins (Table 3, Supplementary Tables S2-S6). A total of 34 proteins was identified in the vomitus, the largest group being proteases (32\% of the total emPAI score of 13.52; Fig. 5). These were predominantly isoforms of cathepsin L but asparaginyl endopeptidase, prolidase, leucine amino peptidase, dipeptidyl-peptidase and cathepsin B were also identified, all apparently of lysosomal origin. The second most abundant group (18\%) comprising other secretory proteins, predominantly the Kunitz-type protease inhibitor with one of the highest emPAI scores (2.37) in the entire study, and a lysosomal phospholipase B. Unknown function and carrier proteins were ranked third (16\%) and fourth (12\%), one of the former category (FhB03836) being especially abundant. The carrier category comprised two isoforms of the cholesterol transporter NPC-2, and three variants of Fasciola myoglobin (one annotated as haemoglobin). The vomitus also contained four proteins of host origin (6\%), the alpha and beta chains of haemoglobin being the most abundant, but the heavy chain of immunoglobulin $A$ and serum albumin were also identified. The vomitus was notable for the scarcity of fluke cytosolic ( $<1 \%$; aldolase) and cytoskeletal proteins (4\%; calponin, fimbrin, tubulin) and the absence of chaperones, revealing that up to $2 \mathrm{~h}$ ex-host, in RPMI-1640 medium, the parasites had incurred minimal cell damage leading to protein leakage. This observation may indicate that the presence of the defence protein thioredoxin peroxidase (peroxiredoxin) in the vomitus, also noted by Robinson et al. (2009) represents a true release of into the gut lumen, not leakage due to damage. It is also possible that the phospholipase $\mathrm{A}$ and $\mathrm{D}$ detected in the vomitus are of lysosomal origin (i.e. secretory), although placed here in the membrane-associated category.

Subsequent to the collection of vomitus, selected flukes were incubated for a further hour in a secretion experiment and the released proteins subjected to MS/MS analysis. This extra incubation virtually doubled the number of proteins; two aspects are apparent from their identities (Table 3; Fig. 5). Firstly, the flukes continued to regurgitate vomitus into the medium as evidenced by the detection of certain gut proteases $(18.6 \%$ of the higher total emPAI score 

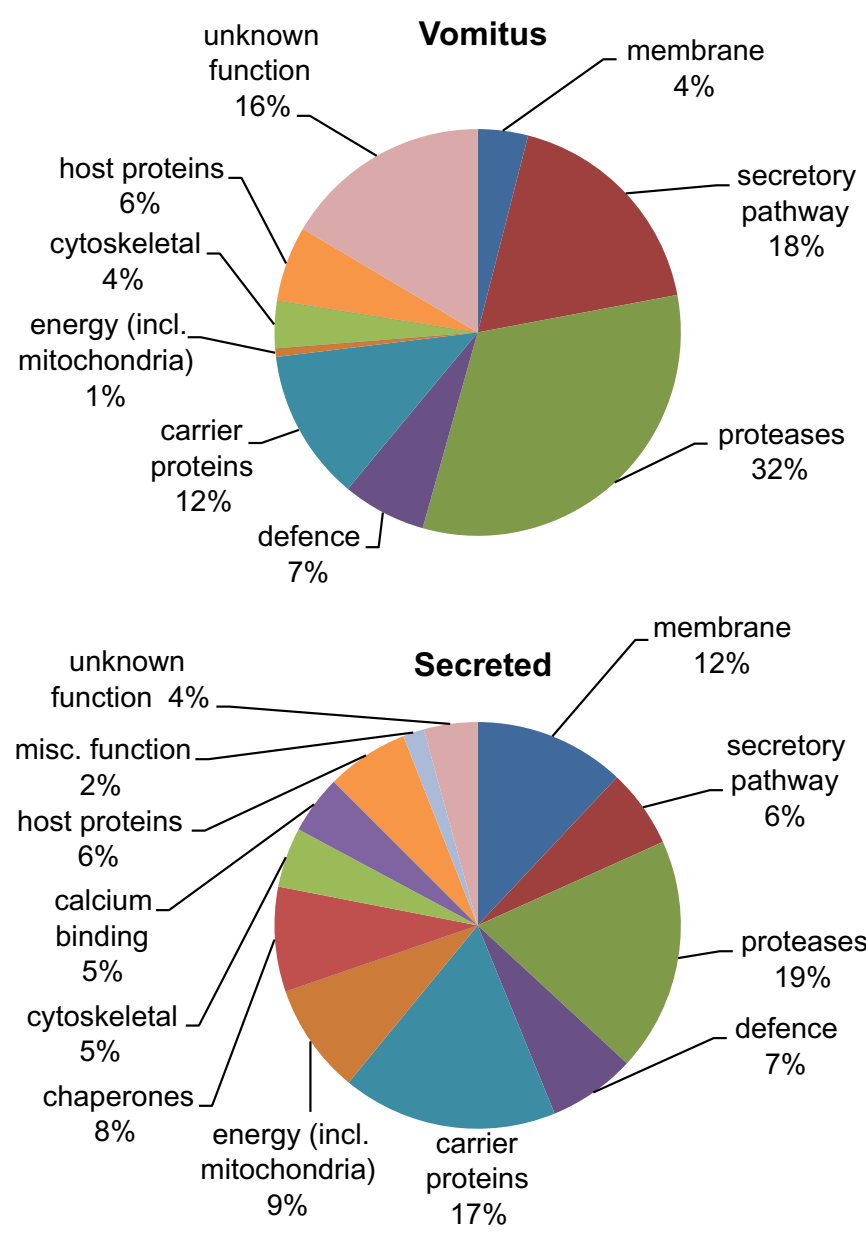

Fig. 5. Pie chart showing the percentage distribution of proteins identified in Vomitus (A) and Secretion (B) preparations on the basis of the exponentially modified Protein Abundance Index (emPAI), classified by biological function.

of 20.15; Fig. 5). Secondly, there was a marked increase in cytosolic proteins, particularly chaperones (8\%) and those involved in energy metabolism (9\%) and defence (9\%). Host haemoglobins alpha and beta as well as the IgA heavy chain were also present in the secretion sample (7\%).

In the membrane category, three annexins, a phospholipase and carbonic anhydrase were found, the last of these being potentially glycosylphosphatidylinositol (GPI)-anchored (cf. S. mansoni, (Castro-Borges et al., 2011)). The detection of a multi-membrane spanning tetraspanin is suggestive of tegument membrane damage. Of particular note in the secretory category was a second isoform of the von Willebrand factor, a serpin, and a nucleoside diphosphate kinase predicted to encode a signal peptide. In the carrier protein category one of the NPC-2 cholesterol transporters was released, and ferritin presumably involved in iron transport. The presence of the cytosolic fatty acid binding protein (Fh15; Table 3) may be further evidence of cellular damage.

\section{Discussion}

The pioneering investigations of the trematode tegument in the early 1960s that defined its cellular organisation at the ultrastructural level were undertaken on F. hepatica (Threadgold, 1963, 1967; Bjoerkman and Thorsell, 1964). However, since that time there has been much less fundamental work on isolation of the tegument or analysis of its protein composition compared with schistosomes so there are few pointers in the literature to sample preparation for proteomics. The principal objective of the present study was to adapt techniques used in recent proteomic analyses of the tegument surface of the blood fluke $S$. mansoni (van Balkom et al., 2005; Braschi et al., 2006; Braschi and Wilson, 2006; Castro-Borges et al., 2011) to the $F$. hepatica tegument. The recent activity in the sequencing of adult $F$. hepatica transcripts by ourselves (unpublished data) and others (Young et al., 2010) meant that an extensive EST database was available to aid identification of peptide mass spectra. By cross-species sequence comparisons we were able to show that many tegument membrane and membrane-associated proteins identified in $S$. mansoni by proteomics were represented by putative orthologues in one or more of the three $F$. hepatica transcript databases available.

The FTV protocol developed for the $S$. mansoni tegument has an advantage in relying on physical methods for the initial isolation and enrichment stages, rather than on extractions involving detergents. It also depends on the integrity of the meshwork of subtegumental circular and longitudinal muscle layers to retain the organelles of the internal tissues. However, it does not prevent leakage of cytosolic proteins from those internal tissues and these must be removed before membrane analysis (Braschi et al., 2006). While the cellular organisation of the F. hepatica and $S$. mansoni teguments is similar, with the machinery for protein synthesis and export residing in cell bodies located beneath the muscle layers (Threadgold, 1967; Morris and Threadgold, 1968), there are important differences. The $F$. hepatica tegument is much thicker (15 $\mu \mathrm{m}$ versus $3-4 \mu \mathrm{m}$ in $S$. mansoni), it contains many more mitochondria, the secretory vesicles are quite distinct in appearance and, instead of the secreted membranocalyx that covers the schistosome tegument (Wilson and Barnes, 1977), there is a prominent glycocalyx (Threadgold, 1967). All of these factors are likely to impact on the techniques for tegument isolation and on the proteins identified. In fact, interrogation of the $F$. hepatica transcriptome for orthologues encoding known S. mansoni tegument proteins revealed many common components. In consequence we might anticipate that similar biological processes occur in the tegument of the two flukes. Indeed, the detection of orthologues for Sm200 and LMWP (with no known functions) may indicate processes unique to, but widespread, in trematodes. In contrast, the identification of 38 proteins in the FTV experiment that have no homology outside the Trematoda, 10 found in other flukes and 10 possessing signal peptides and/or transmembrane domains, suggests the occurrence of Fasciola-specific tegumental processes. This observation is important and justifies further detailed analysis of the tegumental proteome to clarify tegument biological functions.

The tegument preparation released by FTV proved not to be as clean as the one for $S$. mansoni made by the same method (Roberts et al., 1983). The most obvious difference was the presence of numerous mitochondria and expanded secretory vesicles, but also the observation of sperm and a single egg in the S2P fraction, prior to UTCS extraction. We interpret the presence of sperm and egg to indicate there is continuous activity by the fluke reproductive system right up to the instant of freezing, rather than their release by rupture of the fluke body wall, since vitelline cells or shell granules were not evident in electron micrographs of the pellet. It should be noted that $F$. hepatica has a much greater reproductive capacity per parasite (up to 50,000 eggs/day; Moxon et al., 2010) than S. mansoni (200-300 eggs/day; Loker, 1983). Despite this contamination, the extraction scheme that produced a final pellet enriched in membrane proteins can be considered a qualified success. The initial wash step with buffer to yield the S2SS fraction contained largely cytosolic proteins. The extraction of the resultant pellet with a combination of chaotropic agents and non-ionic detergents (UTCS) to remove membrane-associated proteins, produced a FP differing markedly in composition from its predecessors. Indeed, the increase in combined membrane and secretory pathway proteins 
from $4 \%$ to $21 \%$ to $29 \%$ in the FP whilst protease and inhibitor contamination from the gut reduced from $7 \%$ to $0 \%$, is a testament to this difference. Mitochondrial and nuclear fractions were also enriched in the final pellet, which was only to be expected given the morphological observations. In future studies on the Fasciola tegument it will be important to introduce a step early in the preparation procedure, which excludes organelles in order to enrich further the surface membrane contribution to the final pellet.

In the final pellet we identified a number of membrane structural proteins (two annexins, a tetraspanin, three ferlins) that are prominent features of the $S$. mansoni tegument surface. We also identified three transporters (two ion channels and a glucose transporter) and three enzymes (two calpains and carbonic anhydrase) that the tegument surfaces of two flukes have in common. In contrast we did not find any of the phosphohydrolases that are exposed at the $S$. mansoni tegument surface, although the relevant genes are represented in $F$. hepatica cDNA databases. One GTPase and a series of GTP-binding proteins were extracted by the UTCS treatment. Such proteins are usually associated with plasma membranes as components of signalling pathways but no receptors were detected; proteomic studies on the S. mansoni tegument have also failed to identify receptors. Finally, a putative orthologue of human CD59 was identified in the final pellet. This aspect is of considerable interest since human CD59 acts as an inhibitor of the complement pathway, blocking formation of the membrane attack complex after binding of C3 (Huang et al., 2006). At least six CD59-like proteins are encoded in the $S$. mansoni genome, two of which are GPI-anchored at the surface of the schistosome tegument (Castro-Borges et al., 2011); one of these proteins (Smp_019350) is the closest homologue (37\% identical, 52\% conserved amino acids) of the $F$. hepatica protein we identified. Our $F$. hepatica databases contain transcripts for at least four genes encoding the CD59-like proteins, all of which possess the diagnostic CCxxDxCN sequence near the C-terminus (data not shown), and representatives are also present in S. japonicum and Schistosoma haematobium. Their presence in the tegument surface may point to a mechanism, widespread in trematodes, for defence against immune attack that would repay further investigation.

The proteins of the secretory pathway that we identified are also informative about processes occurring in the tegument or at its surface. (The Kunitz-type inhibitor and the proteases of gut origin are dealt with in the discussion of vomitus composition below.) One obvious feature is the identification of four potential glycanbinding lectins. All four genes have orthologues in the $S$. mansoni and $S$. japonicum genomes but no lectins have been reported in the tegument of these two blood flukes. Although the F. hepatica cDNA sequences may be incomplete, at least two (FhA00116 and FhB01221) encode a signal peptide suggesting their secretion to the exterior. It is plausible that these predicted lectins play a role in the binding of glycoproteins for endocytosis (Kerrigan and Brown, 2009) or that they interact with host leucocytes, potentially to subvert host responses (Vasta, 2009). The group of three proteins with little homology in common other than the presence of a CUB domain, is more enigmatic. FhC02219 encodes a signal peptide and is likely secreted, and the other two transcripts may lack the $5^{\prime}$ end. In vertebrates, CUB domains are present in diverse proteins. A conserved domain search on NCBInr reveals that the longest FhC transcripts (Fh06620 and Fh06044) each possess two CUB domains and a heterodimerisation interface. They have the closest homology to CUBN type proteins that function on the brush border of the mammalian gut as components of the receptor that acquires vitamin B12 (Andersen et al., 2010). This suggests that the $F$. hepatica CUB proteins may cooperate to bind a protein ligand in the tegument.

Other potential secretory proteins are noteworthy. LMWP, a $8 \mathrm{kDa}$ protein when its putative leader sequence is subtracted, was first cloned in Clonorchis sinensis and is also present in the $S$. mansoni tegument (Castro-Borges et al., 2011). The second is the F. hepatica orthologue of SmKK7, another small protein with homology to the potassium channel blockers of scorpion venom. This protein was first described from the cercarial secretions of $S$. mansoni (Curwen et al., 2006), and has been reported subsequently as released when live adult schistosomes are subjected to mild trypsin treatment (Castro-Borges et al., 2011). Its identification in the S2SS but not the UTCS or FP fractions could be taken as evidence that it is a cytoplasmic protein, were it not that the presence of a leader sequence implies export into the endoplasmic reticulum. Both proteins appear to be trematode-specific but their precise tegumental location requires confirmation. The final protein in this group (FhC00742), present in the UTCS fraction, contains a von Willebrand factor domain in association with an N-terminal inter-alpha trypsin inhibitor (ITI) domain, and a metal ion-dependent adhesion site (MIDAS). In humans the von Willebrand factor is required for normal haemostasis and mediates the adhesion of platelets to sites of vascular damage and exposed connective tissue, whereas the ITI domain plays a role in extracellular matrix stabilisation (Sadler, 1998). The role of this protein in the F. hepatica tegument and/or its secretions needs to be investigated.

The experiments in which flukes were incubated in vitro for short periods were intended to provide information about tegument secretions. Unfortunately, these experiments suffered a singular disadvantage compared with similar studies with $S$. mansoni. The blood fluke is very reluctant to open its mouth and regurgitate gut contents when placed in vitro so the live flukes can be exposed to biotinylation reagents (Braschi and Wilson, 2006) or tegument shaving enzymes (Castro-Borges et al., 2011) without the presence of competing proteins or large amounts of proteases. Fasciola hepatica, on the other hand, readily regurgitates a continuous stream of vomitus into the medium. Our attempt to solve this problem by performing a $30 \mathrm{~min}$ pre-incubation provided a vomitus preparation for analysis. However, when clean flukes lacking gut pigment were selected for further incubation, proteomic analysis of the released material merely confirmed the continued secretion of known gut proteases and the Kunitz inhibitor. It is notable that the tegument of the adult flukes at the start of the secretion experiment, after approximately $1 \mathrm{~h}$ in vitro, had a normal appearance, whereas at the end of the $1 \mathrm{~h}$ incubation period in RPMI-1640 medium at $37^{\circ} \mathrm{C}$, vesicles much smaller than the type 2 secretory inclusions were present in the surface pits. Presumably of cytosolic origin, they may explain why more glycolytic enzymes, chaperones, cytoskeletal proteins and calcium binding proteins were identified in the secretions than in the initial vomitus. We infer from this information that any component identified in the initial vomitus preparation is likely to be of gut origin.

Analysis of primary vomitus confirmed the previously described dominance of proteases, specifically cathepsin L and B isoforms, together with the pro-protein convertase asparaginyl endopeptidase and a prolidase (Morphew et al., 2007; Robinson et al., 2008, 2009). Whether the considerable diversity of cathepsin L, cathepsin B and asparaginyl endopeptidase isoforms represents gene family expansion, allelic variation or even errors arising from single-pass sequencing, will only be resolved after the $F$. hepatica genome has been sequenced and annotated. The Kunitz-type serine protease inhibitor is arguably the most abundant protein in the secretions and its high concentration in the primary vomitus confirms its gut origin. It was originally identified by protein sequencing of the major peak of an ethanol extract of fluke homogenate (Bozas et al., 1995). Its apparent mol. wt of $9 \mathrm{kDa}$ reduces to $6.5 \mathrm{kDa}$ if the signal peptide is subtracted, much smaller than mouse or human orthologues. It has been argued that it has a role in preventing blood clotting (Bozas et al., 1995), as occurs in other blood feeding parasites (ticks, hookworms) although an orthologue was not 
found in the S. mansoni vomitus (Hall et al., 2011). The detection of leucine amino peptidase accords with a recent observation that this enzyme is a component of $F$. hepatica excretory and secretory products (Marcilla et al., 2008) and it has been proposed as a vaccine candidate (Piacenza et al., 1999; Acosta et al., 2008). However, according to MEROPS (http://merops.sanger.ac.uk) leucine amino peptidases have an intracellular location and are involved in degradation of oligopeptides. In human serum, leucine amino peptidase is used as a marker for hepatocyte damage. Its identification in $F$. hepatica vomitus may not reflect true secretion but simply an artefact due to tissue damage, as it has not been identified in S. mansoni vomitus (Hall et al., 2011). Our proteomic analysis of the vomitus and secretion preparations expands the list of known $F$. hepatica gut proteases by adding a serine carboxypeptidase, hitherto only inferred from transcript data (Robinson et al., 2009), and a dipeptidyl peptidase. It is notable that both $S$. mansoni and $F$. hepatica vomitus contain a prolyl-carboxypeptidase which may be involved in the hydrolysis of bulky serum proteins such as albumin (Robinson et al., 2009; Hall et al., 2011). In the case of $F$. hepatica the prolidase-type enzymes may additionally hydrolyse proline-rich connective tissue collagens.

The objective of the incubation experiment with washed live flukes was to collect tegument secretions after the contribution to the medium by gut vomitus had diminished. A small number of proteins in the membrane and membrane-associated categories was more abundant in the secretion fraction. Five of these proteins (carbonic anhydrase, three annexins, tetraspanin) were also found in the FTV preparation which provides strong circumstantial evidence for a tegument surface location. In S. mansoni, at least one tetraspanin elicits protection against cercarial challenge (Tran et al., 2006) whilst a surface annexin has been proposed as a vaccine candidate (Tararam et al., 2010). On that basis the $F$. hepatica orthologues would repay investigation for protective potential. It is surprising that none of the lectins or CUB-domain proteins identified in the UTCS and/or FP after FTV were detected in the secreted material, as at least three possess signal peptides. Conversely, the three phospholipases (FhB00083; FhB00054; FhB00284) assigned to the membrane/membrane associated or secretory categories may well prove to be of gut origin, especially as all three were found in the primary vomitus, as well as the secretions. Finally, a second ITI/von Willebrand factor type protein was found in the secretion sample (FhC01779, showing 45\% identical, 63\% conserved amino acids with FhC00742 in the UTCS fraction), emphasising the possible tegumental role for these unusual proteins.

The $F$. hepatica vomitus/secretions samples contained the carrier proteins NPC-2 and ferritin, in common with the vomitus of S. mansoni (Hall et al., 2011), but no saposins that are prominent in the blood fluke; this is surprising as a saposin has been identified in excretory-secretory products of $F$. hepatica by Western blotting (Espino and Hillyer, 2003). The detection of the host proteins in the secretion sample indicates that the $30 \mathrm{~min}$ pre-incubation did not achieve complete wash-out of the gut contents, while the presence of haemoglobin alpha and beta chains in the vomitus together with albumin (the most abundant plasma protein) confirms the importance of blood in the fluke diet, especially as no bovine epithelial proteins were detected. The IgA heavy chain constant region was the only immunoglobulin identified, perhaps an indication that this class may be the most resistant to proteolysis. This observation suggests that design of a Fasciola vaccine to elicit mucosal responses might be profitable, especially if the IgA class is the most resistant to cathepsin attack.

Characterisation of the $F$. hepatica tegument surface and its secretions was not as straightforward as anticipated, based on previous experience with $S$. mansoni. With hindsight, a major factor is that the gut occupies a much greater proportion of the body mass in F. hepatica than in S. mansoni. For F. hepatica the value is $57 \%$ (using surface area as the measure; Dawes, 1968) whereas for $S$. mansoni the values for male and female worms are $6 \%$ and $16 \%$, respectively (mean $11 \%$, using cross-sectional area; unpublished observations). This discrepancy, coupled with the propensity of $F$. hepatica to vomit, which does not happen with $S$. mansoni, floods the medium with large amounts of interfering proteins that include a rich mixture of proteases. It is clear that collection of $F$. hepatica tegument secretions and enzymatic shaving (Castro-Borges et al., 2011) or biotinylation (Braschi and Wilson, 2006) of exposed proteins on the surface of live flukes, will only be achieved if production of vomitus can be prevented. A second impediment is that the FTV method to investigate surface composition releases not only the tegument membranes, but also its cytoplasm, rich in mitochondria and type 2 secretory vesicles. These inclusions need to be depleted from the preparation before proteomic analysis. A combination of density gradient and differential centrifugation might alleviate the problem, as advocated for S. mansoni tegument membranes (Roberts et al., 1983) and tegument discoid granules (MacGregor et al., 1988).

\section{Acknowledgements}

This research was supported by a Researcher Exchange award from the ARC/NHMRC Research Network for Parasitology, Australia and the Australian Society for Parasitology, and with funds from Charles Sturt University and La Trobe University, Australia. We acknowledge the assistance of Dr. Naveed Aziz and Ms. Celina Whalley of the Genomics Laboratory, Technology Facility, Department of Biology, University of York, UK, in performing the Roche454 sequencing of $F$. hepatica transcripts that were assembled into the contigs and singlets comprising the FhB dataset. Current research in the Gasser Laboratory is supported mainly through grants from the Australian Research Council (ARC), the National Health and Medical Research Council (NHMRC) and Melbourne Water Corporation, Australia. Support from the Victorian Life Sciences Computation Initiative (VLSCI) and the IBM 'Collaboratory' is gratefully acknowledged (RBG).

\section{Appendix A. Supplementary data}

Supplementary data associated with this article can be found, in the online version, at doi:10.1016/j.ijpara.2011.08.003.

\section{References}

Acosta, D., Cancela, M., Piacenza, L., Roche, L., Carmona, C., Tort, J.F., 2008. Fasciola hepatica leucine aminopeptidase, a promising candidate for vaccination against ruminant fasciolosis. Mol. Biochem. Parasitol. 158, 52-64.

Andersen, C.B., Madsen, M., Storm, T., Moestrup, S.K., Andersen, G.R., 2010. Structural basis for receptor recognition of vitamin-B(12)-intrinsic factor complexes. Nature 464, 445-448.

Bjoerkman, N., Thorsell, W., 1964. On the fine structure and resorptive function of the cuticle of the liver fluke, Fasciola hepatica L.. Exp. Cell Res. 33, 319-329.

Bozas, S.E., Panaccio, M., Creaney, J., Dosen, M., Parsons, J.C., Vlasuk, G.V., Walker, I.D., Spithill, T.W., 1995. Characterisation of a novel Kunitz-type molecule from the trematode Fasciola hepatica. Mol. Biochem. Parasitol. 74, 19-29.

Braschi, S., Curwen, R.S., Ashton, P.D., Verjovski-Almeida, S., Wilson, A., 2006. The tegument surface membranes of the human blood parasite Schistosoma mansoni: a proteomic analysis after differential extraction. Proteomics 6, 1471-1482.

Braschi, S., Wilson, R.A., 2006. Proteins exposed at the adult schistosome surface revealed by biotinylation. Mol. Cell. Proteomics 5, 347-356.

Cardoso, F.C., Macedo, G.C., Gava, E., Kitten, G.T., Mati, V.L., de Melo, A.L., Caliari, M.V., Almeida, G.T., Venancio, T.M., Verjovski-Almeida, S., Oliveira, S.C., 2008 Schistosoma mansoni tegument protein Sm29 is able to induce a Th1-type of immune response and protection against parasite infection. PLoS Negl. Trop. Dis. 2, e308.

Castro-Borges, W., Dowle, A., Curwen, R., Thomas-Oates, J., Wilson, R.A., 2011. Mass spectrometric identification of exposed proteins on the surface of the schistosome tegument released by enzymatic shaving: a rational approach for selection of vaccine candidates. PLoS Negl. Trop. Dis. 5, e993. 
Chung, S.Y., Hill, W.E., Doty, P., 1978. Characterization of the histone core complex. Proc. Natl. Acad. Sci. USA 75, 1680-1684.

Curwen, R.S., Ashton, P.D., Sundaralingam, S., Wilson, R.A., 2006. Identification of novel proteases and immunomodulators in the secretions of schistosome cercariae that facilitate host entry. Mol. Cell. Proteomics 5, 835-844.

Dalton, J.P., Joyce, P., 1987. Characterization of surface glycoproteins and proteins of different developmental stages of Fasciola hepatica by surface radiolabeling. J. Parasitol. 73, 1281-1284.

Dalton, J.P., McGonigle, S., Rolph, T.P., Andrews, S.J., 1996. Induction of protective immunity in cattle against infection with Fasciola hepatica by vaccination with cathepsin L proteinases and with hemoglobin. Infect. Immun. 64, 5066-5074.

Dalton, J.P., Skelly, P., Halton, D.W., 2004. Role of the tegument and gut in nutrient uptake by parasitic platyhelminths. Can. J. Zool. 82, 211-232.

Dawes, B., 1968. The Trematoda. Cambridge University Press, Cambridge, UK.

Espino, A.M., Hillyer, G.V., 2003. Molecular cloning of a member of the Fasciola hepatica saposin-like protein family. J. Parasitol. 89, 545-552.

Espino, A.M., Hillyer, G.V., 2004. A novel Fasciola hepatica saposin-like recombinant protein with immunoprophylactic potential. J. Parasitol. 90, 876-879.

Fairweather, I., 2009. Triclabendazole progress report, 2005-2009: an advancement of learning? J. Helminthol. 83, 139-150.

Golden, O., Flynn, R.J., Read, C., Sekiya, M., Donnelly, S.M., Stack, C., Dalton, J.P., Mulcahy, G., 2010. Protection of cattle against a natural infection of Fasciola hepatica by vaccination with recombinant cathepsin L1 (rFhCL1). Vaccine 28 , 5551-5557.

Hall, S.L., Braschi, S., Truscott, M., Mathieson, W., Cesari, I.M., Wilson, R.A., 2011. Insights into blood feeding by schistosomes from a proteomic analysis of worm vomitus. Mol. Biochem. Parasitol. 179, 18-29.

Hamilton, C.M., Dowling, D.J., Loscher, C.E., Morphew, R.M., Brophy, P.M., O'Neill, S.M., 2009. The Fasciola hepatica tegumental antigen suppresses dendritic cell maturation and function. Infect. Immun. 77, 2488-2498.

Hillyer, G.V., 2005. Fasciola antigens as vaccines against fascioliasis and schistosomiasis. J Helminthol 79, 241-247.

Hoyle, D.V., Dalton, J.P., Chase-Topping, M., Taylor, D.W., 2003. Pre-exposure of cattle to drug-abbreviated Fasciola hepatica infections: the effect upon subsequent challenge infection and the early immune response. Vet. Parasitol. $111,65-82$.

Huang, Y., Qiao, F., Abagyan, R., Hazard, S., Tomlinson, S., 2006. Defining the CD59C9 binding interaction. J. Biol. Chem. 281, 27398-27404.

Ishihama, Y., Oda, Y., Tabata, T., Sato, T., Nagasu, T., Rappsilber, J., Mann, M., 2005 Exponentially modified protein abundance index (emPAI) for estimation of absolute protein amount in proteomics by the number of sequenced peptides per protein. Mol. Cell. Proteomics 4, 1265-1272.

Kerrigan, A.M., Brown, G.D., 2009. C-type lectins and phagocytosis. Immunobiology 214, 562-575.

Lammas, D.A., Duffus, W.P., Taylor, D.W., 1985. Identification of surface proteins of juvenile stages of Fasciola hepatica. Res. Vet. Sci. 38, 248-249.

Loker, E.S., 1983. A comparative study of the life-histories of mammalian schistosomes. Parasitology 87, 343-369.

MacGregor, A.N., Kusel, J.R., Wilson, R.A., 1988. Isolation and characterisation of discoid granules from the tegument of adult Schistosoma mansoni. Parasitol. Res. $74,250-254$

Marcilla, A., De la Rubia, J.E., Sotillo, J., Bernal, D., Carmona, C., Villavicencio, Z., Acosta, D., Tort, J., Bornay, F.J., Esteban, J.G., Toledo, R., 2008. Leucine aminopeptidase is an immunodominant antigen of Fasciola hepatica excretory and secretory products in human infections. Clin. Vaccine Immunol. 15, 95-100.

Mas-Coma, S., Bargues, M.D., Valero, M.A., 2005. Fascioliasis and other plant-borne trematode zoonoses. Int. J. Parasitol. 35, 1255-1278.

McManus, D.P., Dalton, J.P., 2006. Vaccines against the zoonotic trematodes Schistosoma japonicum, Fasciola hepatica and Fasciola gigantica. Parasitology 133 (Suppl.), S43-S61.

Morphew, R.M., Wright, H.A., LaCourse, E.J., Woods, D.J., Brophy, P.M., 2007. Comparative proteomics of excretory-secretory proteins released by the liver fluke Fasciola hepatica in sheep host bile and during in vitro culture ex host. Mol. Cell. Proteomics 6, 963-972.

Morris, G.P., Threadgold, L.T., 1968. Ultrastructure of the tegument of adult Schistosoma mansoni. J. Parasitol. 54, 15-27.

Morrison, C.A., Colin, T., Sexton, J.L., Bowen, F., Wicker, J., Friedel, T., Spithill, T.W. 1996. Protection of cattle against Fasciola hepatica infection by vaccination with glutathione $S$-transferase. Vaccine 14, 1603-1612.
Moxon, J.V., LaCourse, E.J., Wright, H.A., Perally, S., Prescott, M.C., Gillard, J.L., Barrett, J., Hamilton, J.V., Brophy, P.M., 2010. Proteomic analysis of embryonic Fasciola hepatica: characterization and antigenic potential of a developmentally regulated heat shock protein. Vet. Parasitol. 169, 62-75.

Mulvenna, J., Moertel, L., Jones, M.K., Nawaratna, S., Lovas, E.M., Gobert, G.N., Colgrave, M., Jones, A., Loukas, A., McManus, D.P., 2010a. Exposed proteins of the Schistosoma japonicum tegument. Int. J. Parasitol. 40, 543-554.

Mulvenna, J., Sripa, B., Brindley, P.J., Gorman, J., Jones, M.K., Colgrave, M.L., Jones, A. Nawaratna, S., Laha, T., Suttiprapa, S., Smout, M.J., Loukas, A., 2010b. The secreted and surface proteomes of the adult stage of the carcinogenic human liver fluke Opisthorchis viverrini. Proteomics 10, 1063-1078.

Piacenza, L., Acosta, D., Basmadjian, I., Dalton, J.P., Carmona, C., 1999. Vaccination with cathepsin $\mathrm{L}$ proteinases and with leucine aminopeptidase induces high levels of protection against fascioliasis in sheep. Infect. Immun. 67, 1954-1961.

Piedrafita, D., Estuningsih, E., Pleasance, J., Prowse, R., Raadsma, H.W., Meeusen, E.N., Spithill, T.W., 2007. Peritoneal lavage cells of Indonesian thin-tail sheep mediate antibody-dependent superoxide radical cytotoxicity in vitro against newly excysted juvenile Fasciola gigantica but not juvenile Fasciola hepatica. Infect. Immun. 75, 1954-1963.

Piedrafita, D., Parsons, J.C., Sandeman, R.M., Wood, P.R., Estuningsih, S.E., Partoutomo, S., Spithill, T.W., 2001. Antibody-dependent cell-mediated cytotoxicity to newly excysted juvenile Fasciola hepatica in vitro is mediated by reactive nitrogen intermediates. Parasite Immunol. 23, 473-482.

Piedrafita, D., Raadsma, H.W., Prowse, R., Spithill, T.W., 2004. Immunology of the host-parasite relationship in fasciolosis (Fasciola hepatica and Fasciola gigantica). Can. J. Zool. 82, 233-250.

Reynolds, E.S., 1963. The use of lead citrate at high $\mathrm{pH}$ as an electron-opaque stain in electron microscopy. J. Cell Biol. 17, 208-212.

Roberts, J.A., Estuningsih, E., Wiedosari, E., Spithill, T.W., 1997. Acquisition of resistance against Fasciola gigantica by Indonesian thin tail sheep. Vet. Parasitol. 73, 215-224.

Roberts, S.M., MacGregor, A.N., Vojvodic, M., Wells, E., Crabtree, J.E., Wilson, R.A., 1983. Tegument surface membranes of adult Schistosoma mansoni: development of a method for their isolation. Mol. Biochem. Parasitol. 9, 105-127.

Robinson, M.W., Menon, R., Donnelly, S.M., Dalton, J.P., Ranganathan, S., 2009. An integrated transcriptomics and proteomics analysis of the secretome of the helminth pathogen Fasciola hepatica: proteins associated with invasion and infection of the mammalian host. Mol. Cell. Proteomics 8, 1891-1907.

Robinson, M.W., Tort, J.F., Lowther, J., Donnelly, S.M., Wong, E., Xu, W., Stack, C.M., Padula, M., Herbert, B., Dalton, J.P., 2008. Proteomics and phylogenetic analysis of the cathepsin L protease family of the helminth pathogen Fasciola hepatica: expansion of a repertoire of virulence-associated factors. Mol. Cell. Proteomics 7, 1111-1123.

Sadler, J.E., 1998. Biochemistry and genetics of von Willebrand factor. Annu. Rev. Biochem. 67, 395-424.

Tararam, C.A., Farias, L.P., Wilson, R.A., Leite, L.C., 2010. Schistosoma mansoni Annexin 2: molecular characterization and immunolocalization. Exp. Parasitol. 126, 146-155.

Threadgold, L.T., 1963. The ultrastructure of the "cuticle" of Fasciola hepatica. Exp. Cell Res. 30, 238-242.

Threadgold, L.T., 1967. Electron-microscope studies of Fasciola hepatica. 3. Further observations on the tegument and associated structures. Parasitology 57, 633637

Tran, M.H., Pearson, M.S., Bethony, J.M., Smyth, D.J., Jones, M.K., Duke, M., Don, T.A., McManus, D.P., Correa-Oliveira, R., Loukas, A., 2006. Tetraspanins on the surface of Schistosoma mansoni are protective antigens against schistosomiasis. Nat. Med. 12, 835-840.

Trudgett, A., McNair, A.T., Hoey, E.M., Keegan, P.S., Dalton, J.P., Rima, B.K., Miller, A., Ramasamy, P., 2000. The major tegumental antigen of Fasciola hepatica contains repeated elements. Parasitology 121, 185-191.

van Balkom, B.W., van Gestel, R.A., Brouwers, J.F., Krijgsveld, J., Tielens, A.G., Heck, A.J., van Hellemond, J.J., 2005. Mass spectrometric analysis of the Schistosoma mansoni tegumental sub-proteome. J. Proteome Res. 4, 958-966.

Vasta, G.R., 2009. Roles of galectins in infection. Nat. Rev. Microbiol. 7, 424-438.

Wilson, R.A., Barnes, P.E., 1977. The formation and turnover of the membranocalyx on the tegument of Schistosoma mansoni. Parasitology 74, 61-71.

Young, N.D., Hall, R.S., Jex, A.R., Cantacessi, C., Gasser, R.B., 2010. Elucidating the transcriptome of Fasciola hepatica - a key to fundamental and biotechnological discoveries for a neglected parasite. Biotechnol. Adv. 28, 222-231. 